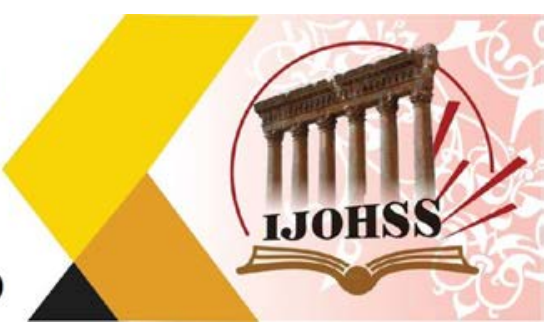

\title{
التحليل الجغرافي لواقع المدارس الاهلية في مدينة الناصرية وافاقها المستقبلية المدارية
}

\author{
م. د. مهدي ناصر حسين الكناني \\ كلية التربية الاساسية فئية \\ جامعة ذي قار

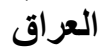

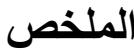

يعد التعليم الاهلي من اهم القطاعات التي ترفد المجتمع بأجيال واعية قادرة على البناء والتتمية والابتكار ، وقد توسع قطاع التعليم الاهلي في العراق بعد عام (2003) بشكل كبير ، اذ تأسست اولى المدارس الاهلية في بلي محافظة ذب قار عام 2007، و فتحت آنذاك اربع مدارس اهلية في مركز مدينة الناصرية خلال ذلك العام . يهدف البحث الى دراسة و اقع التعليم الاهلي في مدينة الناصرية ثم بيان العو امل الجغر افية المؤثرة على التوزيع المكاني للمدارس ، وقد تم الاعتماد على المنهج التحليلي واعتماد الاساليب الاحصائية في دراسة التغيرات

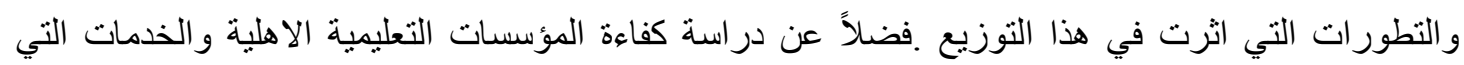
تؤديها قياساً بالمعايير المحلية و العالمية. تبين من خلال نتائج البحث وجود تطور كبير في قطاع التعليم الاهلي في مدينة الناصرية خلال السنوات الاخيرة ، اذ بلغ عدد رياض الاطفال لعام 2018 (11) روضة ، في حين بلغ عدد المدارس الابتدائية (42) مدرسة، اما لئل المدارس الثانوية فقد بلغ عددها (48) مدرسة .كما اظهرت الدر اسة عدم وجود انتظام في توزيع رياض الاطفال ، اما بالنسبة الى نطاق خدمة المدارس الابتدائية فقد تبين تركز ها في حي الادارة المحلية وحي البشائر ، اما بالنسبة الى المدارس الثانوية فقد اتضح تركز ها في حي الادارة المحلية وحي البشائر وحي الاسكان القديم وتقل وتكاد تتعدم في الاحياء الاخرى . بأس 


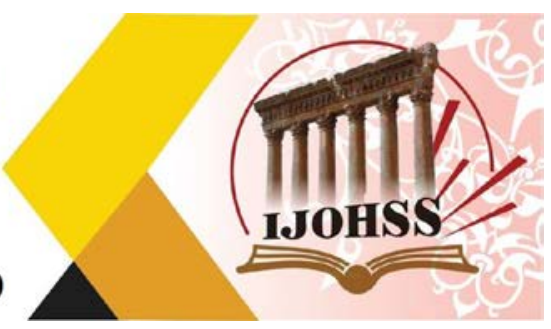

\title{
Geographical Analysis of the Reality of the Private Schools in the City of Nasiriyah and Its Future Prospects
}

\author{
Dr. Mehdi Nasser Hussein Al-Kanani \\ Faculty of Basic Education \\ Dhi Qar University \\ Iraq
}

\begin{abstract}
The private education sector in Iraq expanded significantly after 2003, and the first private schools were established in Dhi Qar Governorate in 2007, with the opening of four public schools in the governorate of Dhi Qar. Nasiriyah city center during this year.

The research aims to study the reality of the private education in the city of Nasiriyah and then the geographical factors affecting the spatial distribution of the schools. The analytical approach was adopted and the statistical methods were adopted in the study of the changes and developments that affected this distribution.

The results of the research show that there has been a significant development in the private education sector in the city of Nasiriyah in recent years. The number of kindergartens in 2018 reached 11 kindergartens while the number of primary schools reached (42), and the number of secondary schools reached (48). The study showed that there is no regularity in the distribution of kindergartens. As for the primary school service, it was found in the local administration district and local Al-Bashar. As for the secondary schools, it was found in the local administration district, local Al-Bashar, and almost lacking in neighborhoods and other.
\end{abstract}

Keywords: geographical analysis, private schools, Nasiriyah. 


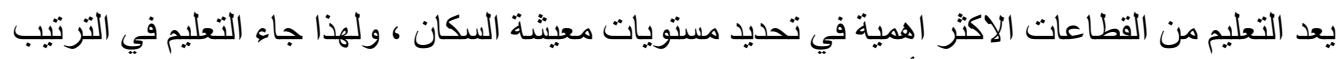

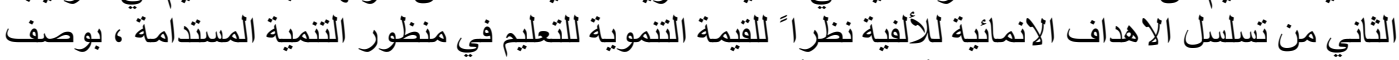

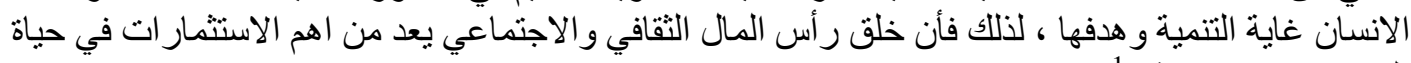

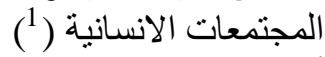

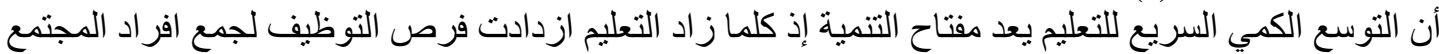

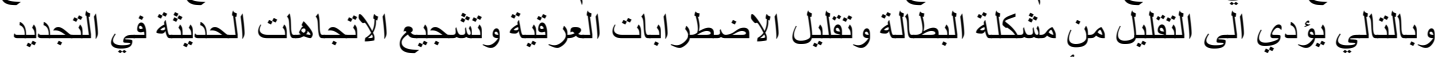

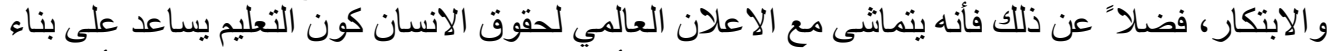

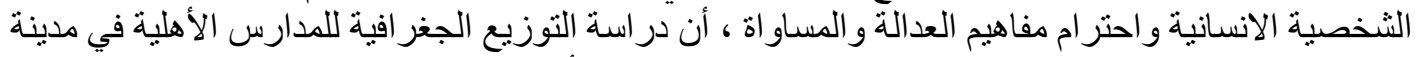

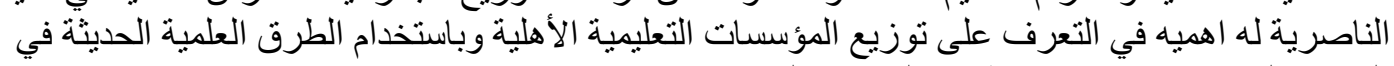

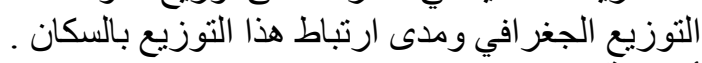

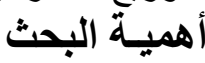

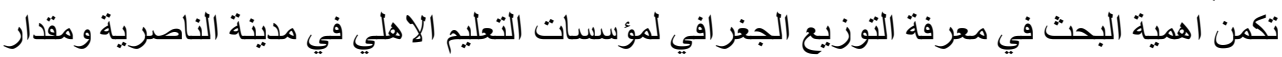

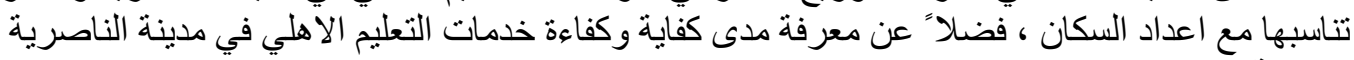

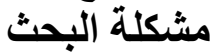

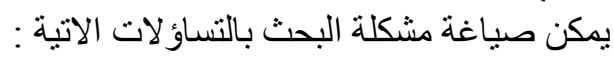

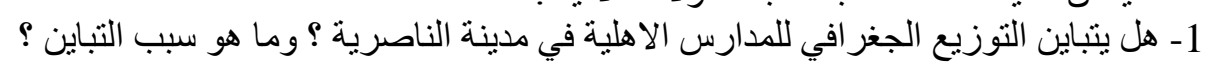

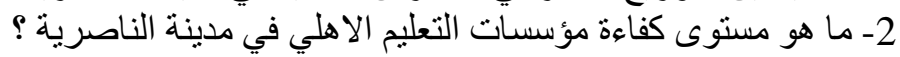

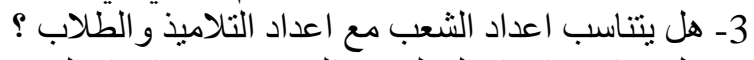

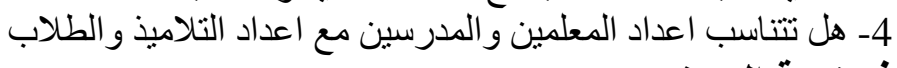
فرضيـة البحث

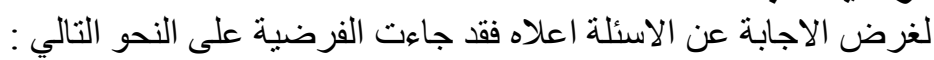

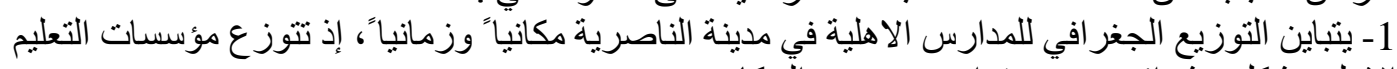

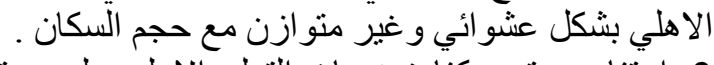

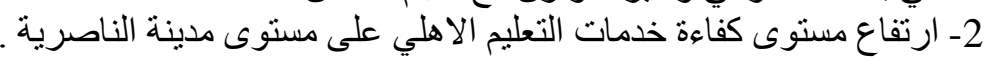

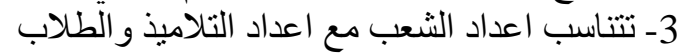

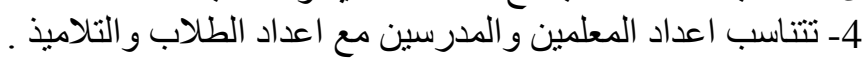
اهداف البحث

1- اعطاء صوره عن البحث التوزيع الحالي لو اقع مؤسسات التعليم الاهلي في منطقة الدر اسة .

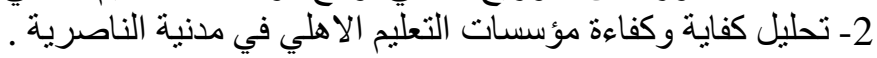

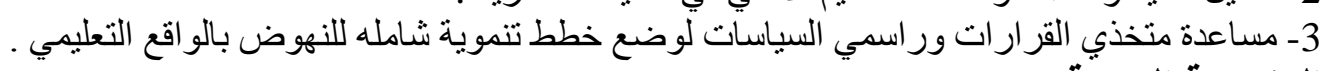

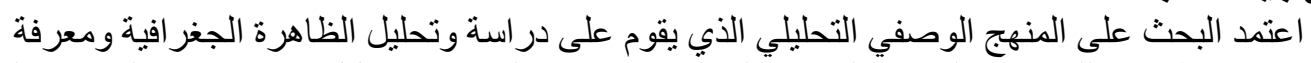

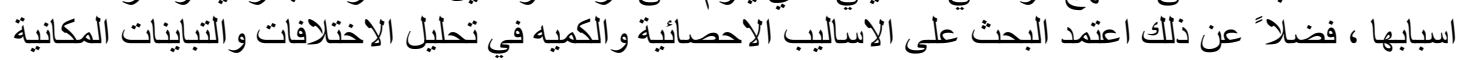

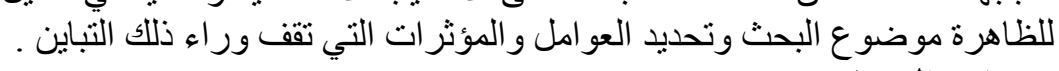
مصادر البحث

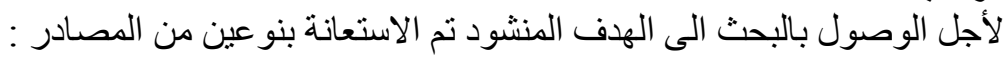

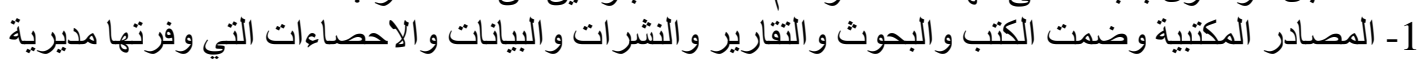
تربية محافظه ذي قار ، قدم التخطيط .

1 - جمهورية العراق ، وزارة التخطيط و التعاون الانمائي ، الجهاز المركزي للإحصاء وتكنلوجيا المعلومات خارطة الحرمان ومستويات المعيثة في العراق ، 2011 ، ص149 


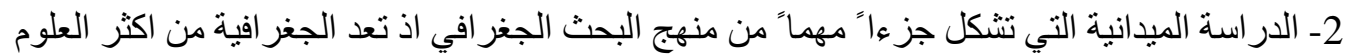

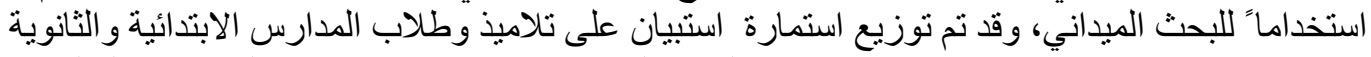

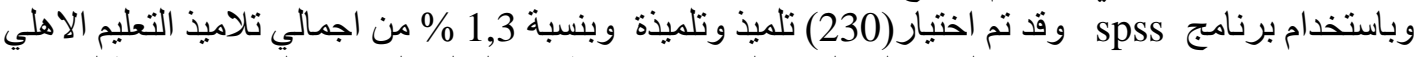

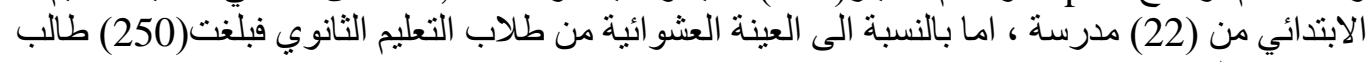
موز عين على (25) مدرسة. حدود منطقة الدراسنة

تتمثل منطقة الدر اسة بمدينة الناصرية احدى مدن محافظة ذي قار جنو

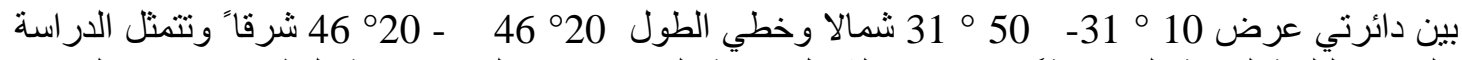

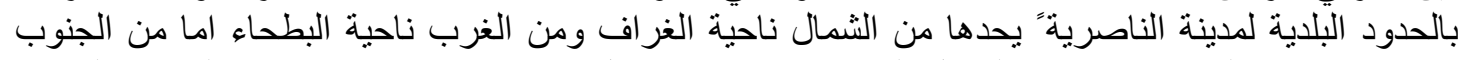

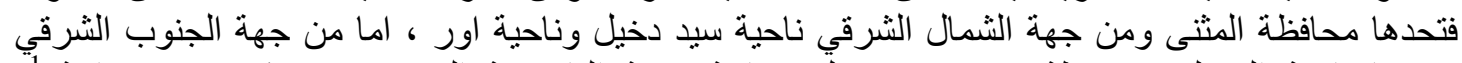

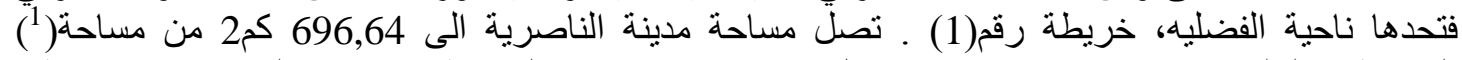
المحافظة والبالغة (137/38) كم2 اي ما يعادل

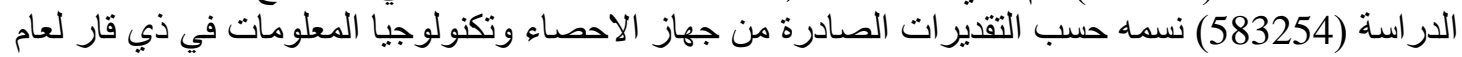


المجلة الحولية اللهلور اللأسانية والإمتماعية International Journal of Humanities and Social Sciences website:www.ijohss.com Email:editor@ijohss.com ISSN: 2415 - 4822 العدد (14) أغسطس 2020 Volume (14) August 2020

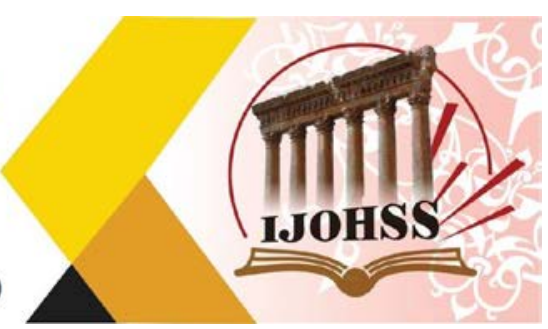
خريطة رقم (1) موقع مدينة الناصرية من العراق ومحافظة ذي قار

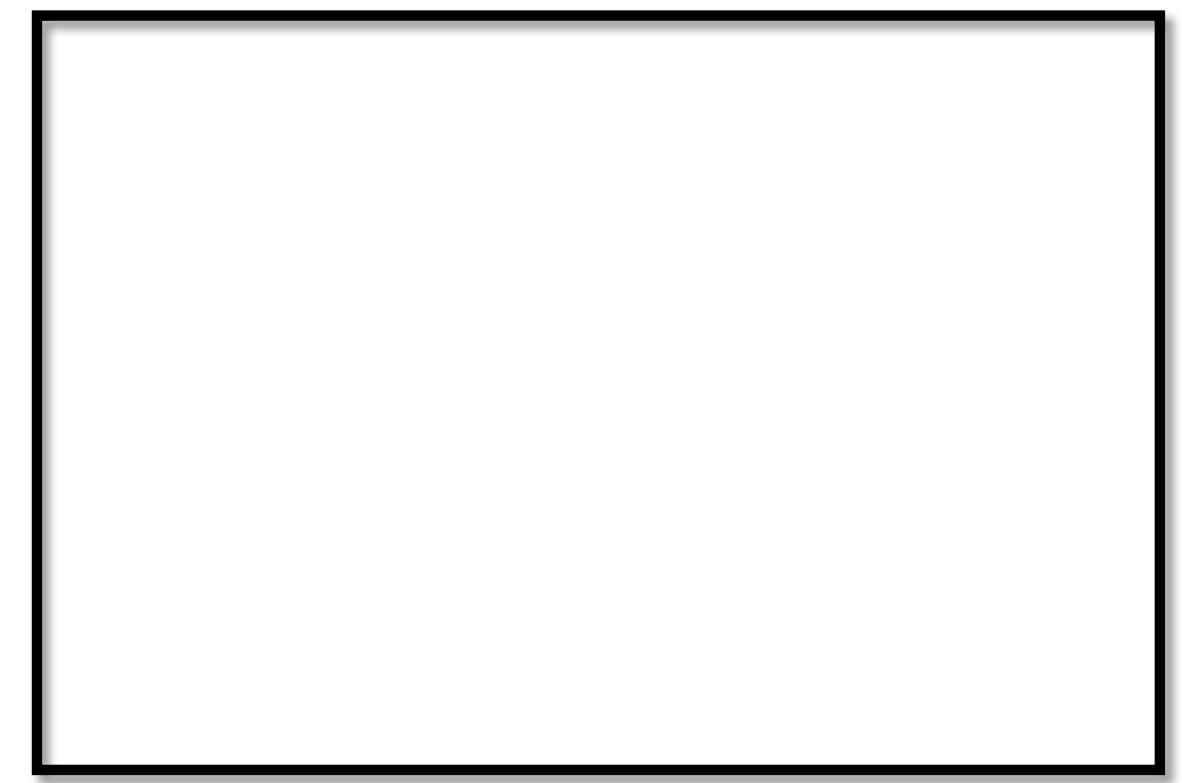

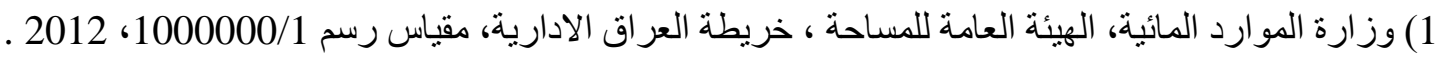

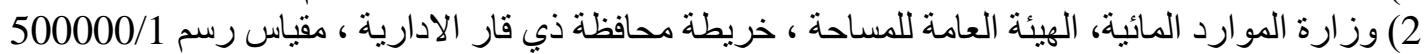
3) مديرية بلدية الناصرية ، قسم نظم المعلومات الجغر الفية، خريطة مدينة الناصرية الادارية المارية ، بيانات غير منشورة، مدايرة 2018 


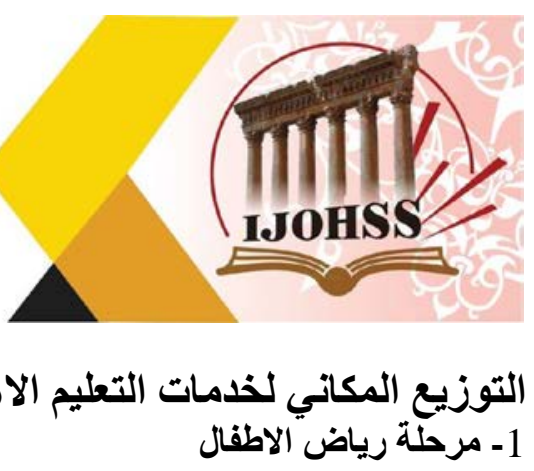

\section{التوزيع المكاني لخدمات التعليم الاهلي في مدينة الناصرية :}

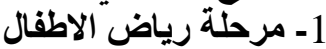

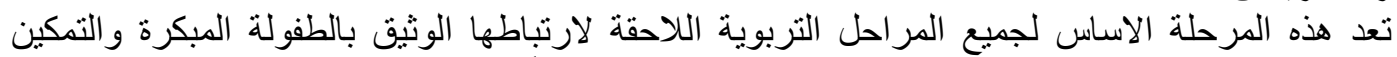

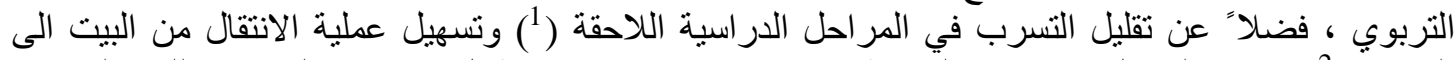

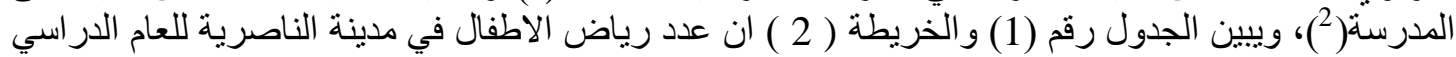

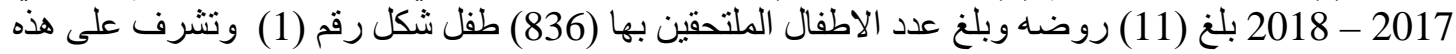

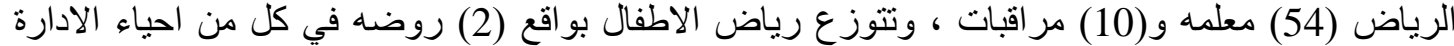

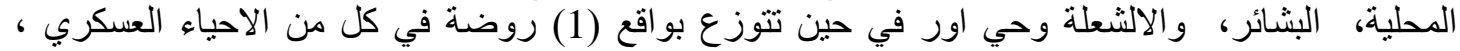

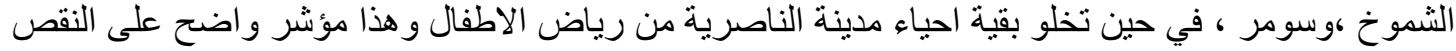

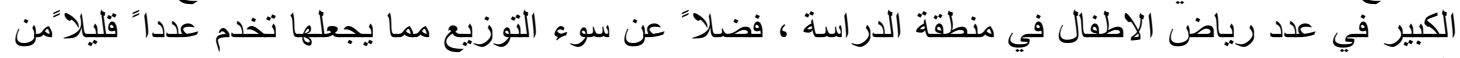

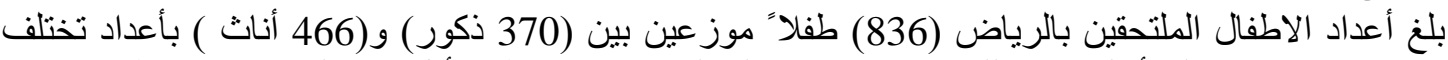

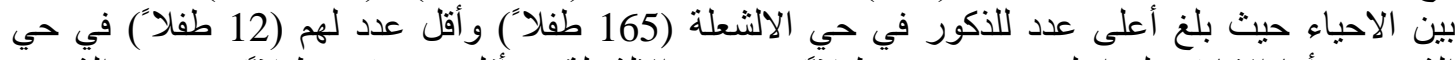

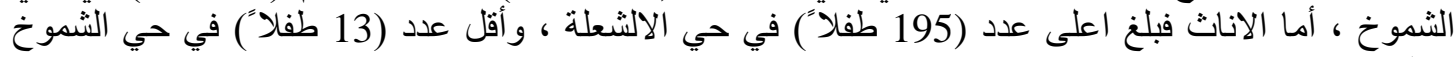

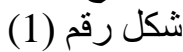

و هذا يرجع الى ان حي الثعلة من الاحياء ذات المستوى المعيثي المرتفع كون اغلب ساكنيه من التجار

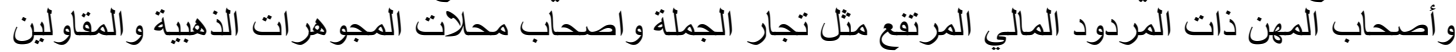

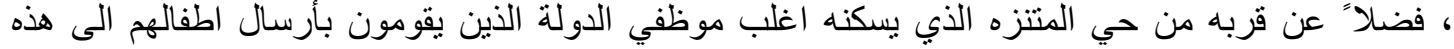

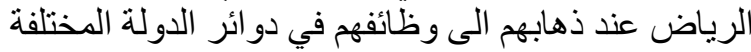

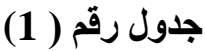

التوزيع المكاني لرياض الاطفال الاهلي في مدينة الناصرية 2018

\begin{tabular}{|c|c|c|c|c|c|c|c|c|c|c|c|c|}
\hline \multicolumn{2}{|c|}{ التعليمية الهيئة } & \multicolumn{3}{|c|}{ الثشــــــع } & \multicolumn{6}{|c|}{ عــــــــد الاطـــــال المســــلين } & \multirow{3}{*}{$\begin{array}{l}y \\
\frac{1}{1} \\
\overline{3} \\
\frac{7}{3}\end{array}$} & \multirow[t]{3}{*}{ والحصلة } \\
\hline \multirow[t]{2}{*}{ مراقبه } & \multirow[t]{2}{*}{ المجموع } & \multirow{2}{*}{$\begin{array}{l}\overline{3} . \\
\text { a } \\
\text { s. }\end{array}$} & \multirow{2}{*}{$\begin{array}{l}\text { 百 } \\
\text { 䊅 }\end{array}$} & \multirow{2}{*}{ 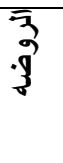 } & \multicolumn{3}{|c|}{ التمهيدي 5 سنوات } & \multicolumn{3}{|c|}{ الروضة 4 سنوات } & & \\
\hline & & & & & المجموع & بنات & بنو & ع المجمو & بنات & بنون & & \\
\hline 2 & 11 & 5 & 3 & 2 & 42 & 25 & 17 & 30 & 17 & 13 & 2 & الادارة المحلية \\
\hline- & 3 & 2 & 1 & 1 & 20 & 9 & 11 & 10 & 4 & 6 & 1 & العسكري \\
\hline 2 & 5 & 2 & 1 & 1 & 13 & 6 & 7 & 12 & 7 & 5 & 1 & الثنموخ \\
\hline- & 9 & 7 & 4 & 3 & 88 & 40 & 48 & 48 & 24 & 24 & 2 & البشائر \\
\hline 1 & 3 & 3 & 2 & 1 & 28 & 14 & 14 & 7 & 4 & 3 & 1 & سومر \\
\hline 3 & 15 & 7 & 3 & 4 & 217 & 122 & 95 & 143 & 73 & 70 & 2 & الالشعلة \\
\hline 2 & 8 & 4 & 2 & 2 & 158 & 109 & 49 & 60 & 12 & 8 & 2 & حي اور \\
\hline 10 & 54 & 30 & 16 & 14 & 566 & 325 & $\begin{array}{r}24 \\
1\end{array}$ & 270 & 141 & 129 & 11 & المجموع \\
\hline
\end{tabular}

المصدر: المديرية العامة للتربية في محافظة ذي قار بيانات غير منشورة في 2018

خريطة رقم (2) التوزيع المكاني لرياض الاطفال الاهلي في مدينة الناصرية

1 - حسين عليوي ناصر الزيادي ، قطاع التربيه و التعليم ، دراسة مقدمه الى دائرة التنمية الاقليمية في محافظة ذي قار ،

2 - شعله اسماعيل العارف ، نظام التعليم في العر اق ، دار الحكمة للطباعة والنشر ،بغداد ، 1993 ، ص90 
المجلة الحولية اللملور اللأسانية والإمتماعية International Journal of Humanities and Social Sciences website:www.ijohss.com Email:editor@ijohss.com العدد (14) أغسطس 2020 ISSN: 2415 - 4822

Volume (14) August 2020
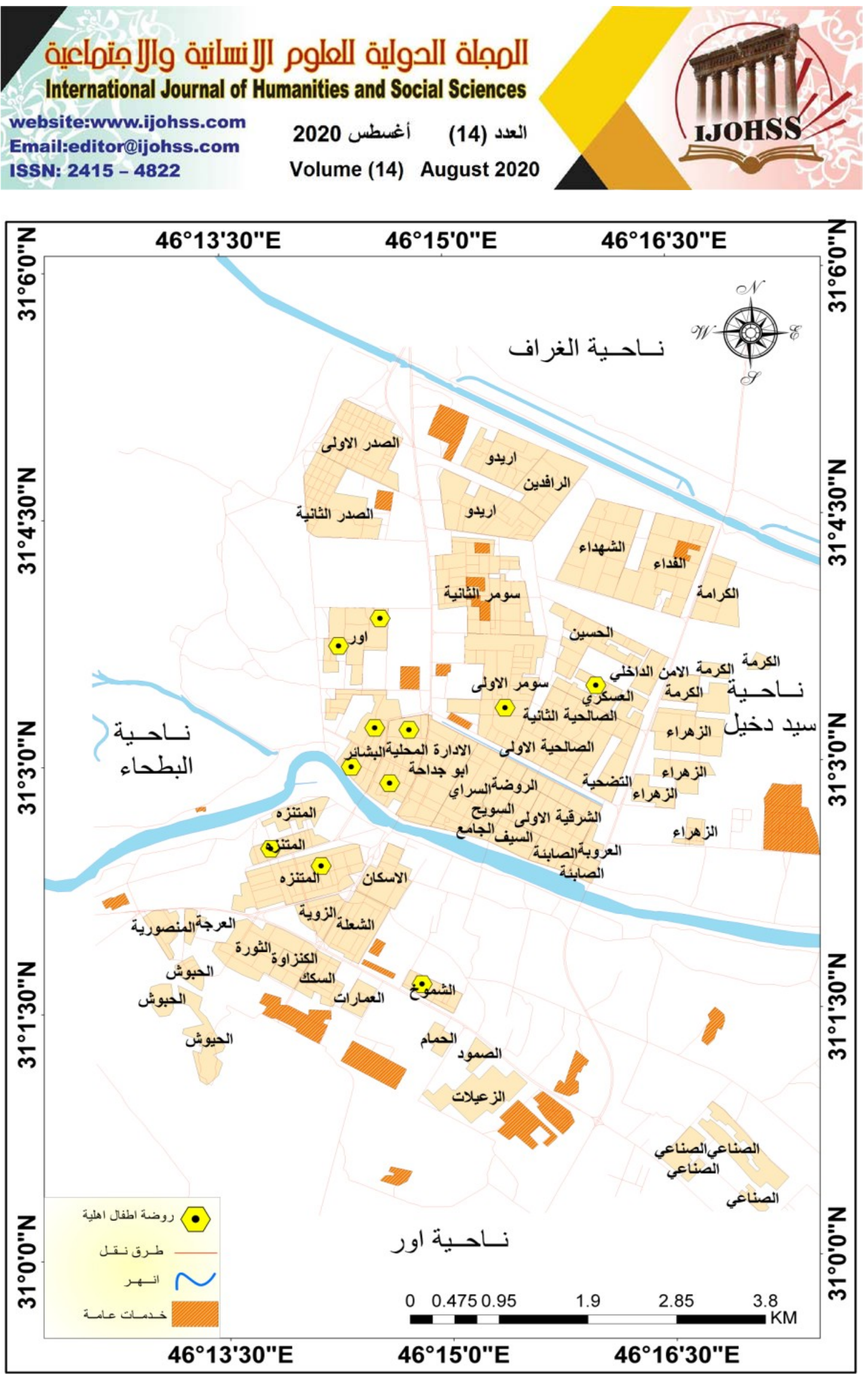

المصدر : الباحث اعتمادا" على بيانات الجدول رقم (1) 
المجلة الحولية اللعلور اللأسانية والإمتماعية International Journal of Humanities and Social Sciences website:www.ijohss.com Email:editor@ijohss.com ISSN: $2415-4822$
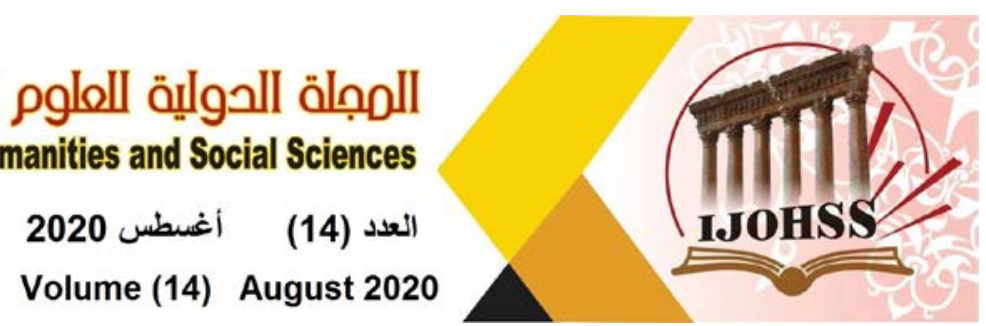

شكل رقم (1) اعداد اطفال الرياض الاهلي في مدينة الناصرية

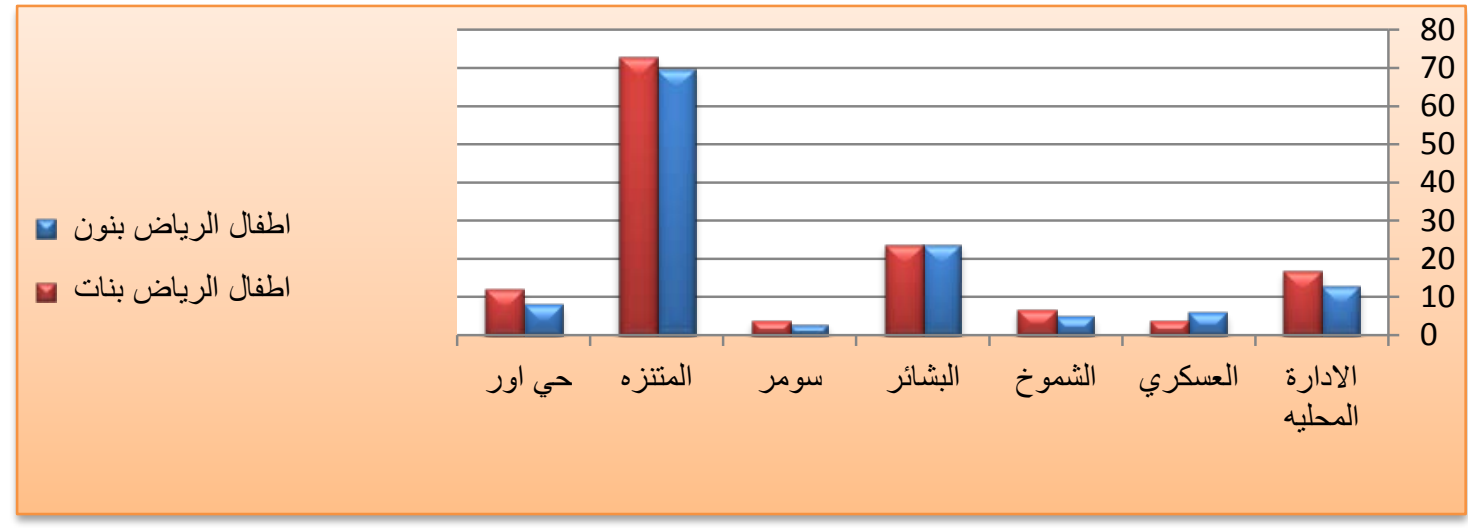

الألصدر : الباحث اعتماداء على بيانات الجدول رقم (1)

2- 2 - 2 مرحلة التعليم الابتدائي :

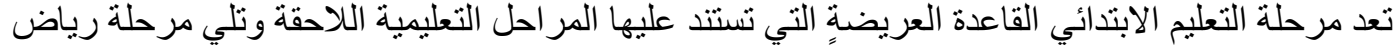

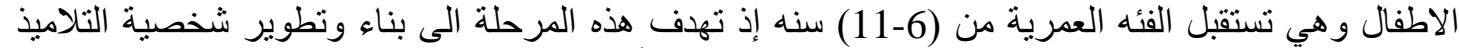

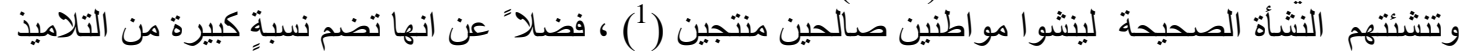

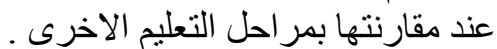
بلغ عدد تلاميذ المدارس الابتدائية الاهلية للعام الدراسي 2017 - 2018 (8276) (8254) تلميذ وتلميذه حيث شكلوا

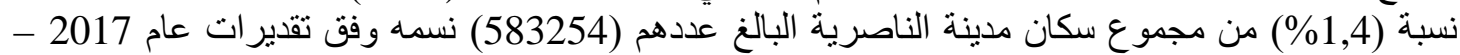

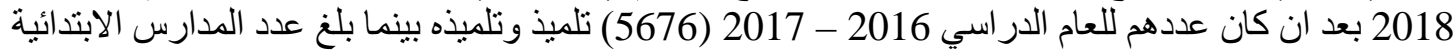

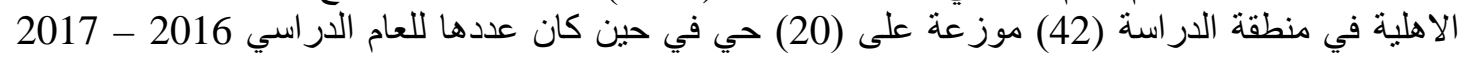

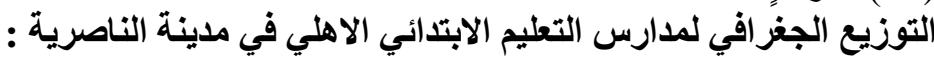

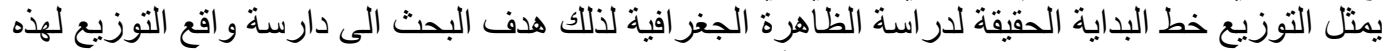

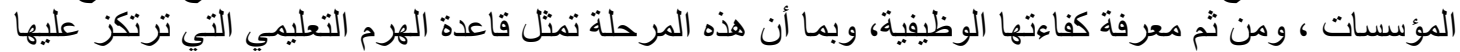

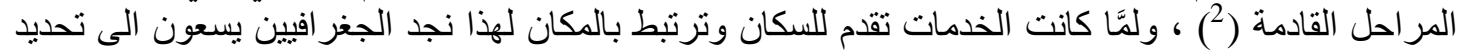

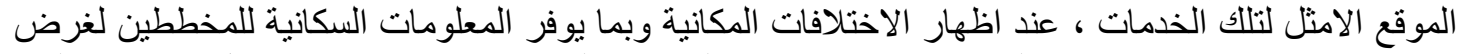

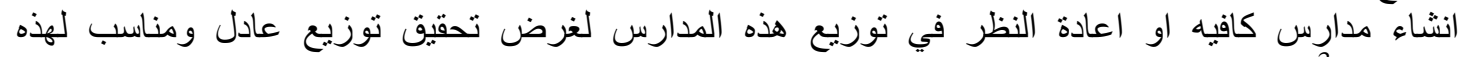

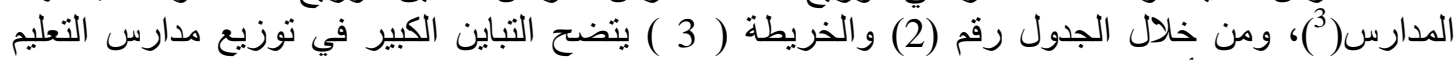

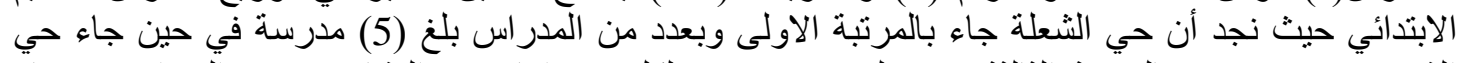

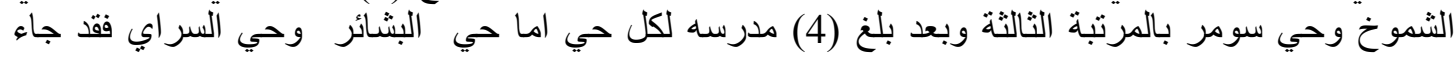

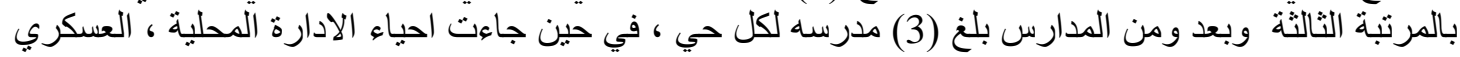

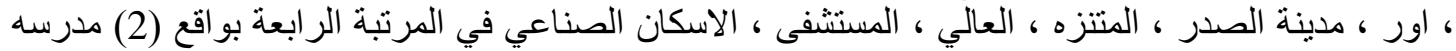

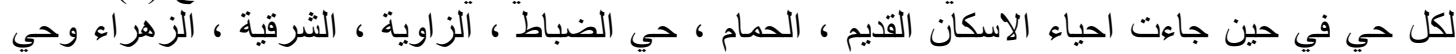

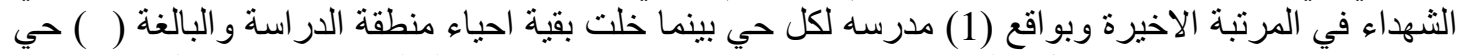

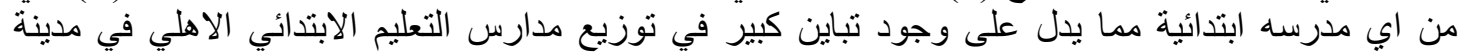

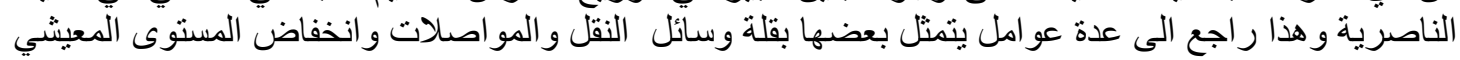

1 - حاتم حمودي حسن ، تحليل و اقع الخدمات التعليمية قضاء الكاظمية، رسالة ماجستير غير منشورة ، كلية الآداب ،

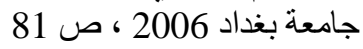
2 - عبد المنعم علي عبد الهادي ابو زيد ، جادي ، جغر افية الخدمات الصحية و التعليمية في محافظة الجيزة ، اطروحة دكتور اه غير

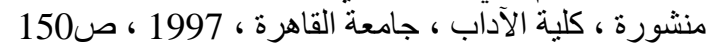
c.cobe, planning the hoctioh of school studies $10<$ uNESCO, $1999<0$ age 183 - 3 


\section{المجلة اللدولية اللملوم الأسانية والإمتصاعية}

International Journal of Humanities and Social Sciences

website:www.ijohss.com

Email:editor@ijohss.com

العدد (14) أغسطس 2020

I.JHSS

ISSN: 2415 - 4822

\section{Volume (14) August 2020}

لساكني هذه الاحياء ، فضلا" عن ان الددارس الاهلية تتطلب مو اصفات خاصه من مساحه و ابنيه يصعب تو تو اجدها

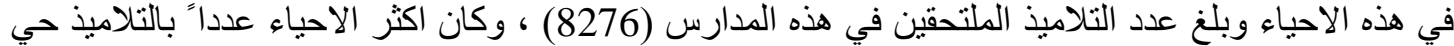

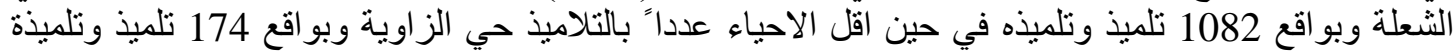

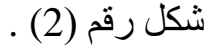

و هذا يعود الى و جود خمس مدارس ابتدائية ضمن هذا الحي ، كما أنت اغلب ساكنيه ذات مستوى معيشي مرتفع

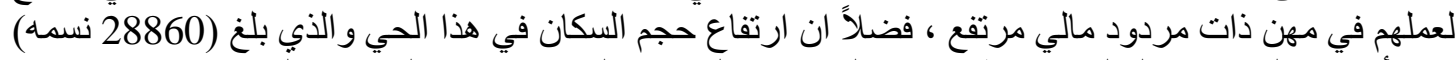

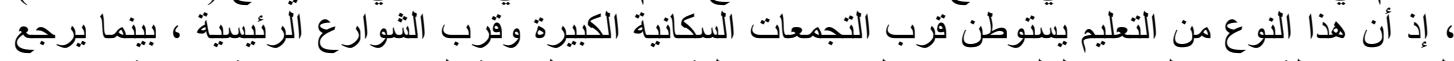

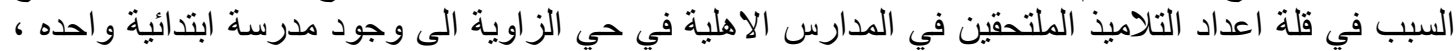

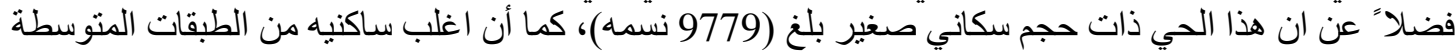

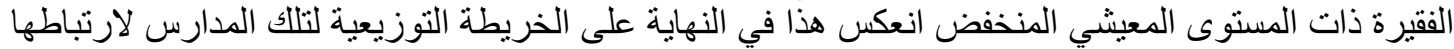

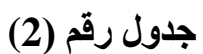

بالسكان و المستوى الاقتصنادي.

\begin{tabular}{|c|c|c|c|c|c|c|}
\hline \multirow{2}{*}{ السكان } & \multirow{2}{*}{ التلاميذ } & \multicolumn{3}{|c|}{ عدد المدارس } & \multirow{2}{*}{ و المحلةِ } & \multirow[t]{2}{*}{ ت } \\
\hline & & مختلط & بنات & بنين & & \\
\hline 15068 & 285 & 2 & - & - & الادارة المحليه & 1 \\
\hline 10066 & 217 & 2 & - & - & الحي العسكري & 2 \\
\hline 26965 & 790 & 4 & - & - & الثموخ & 3 \\
\hline 11970 & 327 & 3 & - & - & البشائر & 4 \\
\hline 41650 & 656 & 4 & - & - & سومر & 5 \\
\hline 28860 & 1082 & 5 & - & - & الالشعلة & 6 \\
\hline 21902 & 457 & 2 & - & - & حي اور & 7 \\
\hline 90160 & 650 & 3 & - & - & السراي & 8 \\
\hline 29770 & 271 & 2 & - & - & مدينة الصدر & 9 \\
\hline 120990 & 504 & 2 & - & - & المتنزه & 10 \\
\hline 11894 & 448 & 2 & - & - & الصالحية & 11 \\
\hline 7889 & 375 & 2 & - & - & المتثشفى & 12 \\
\hline 22623 & 437 & 1 & - & - & الاسكان الصناعي & 13 \\
\hline 11705 & 297 & 1 & - & - & الاسكان القديم & 14 \\
\hline 4785 & 289 & 1 & - & - & الحمام & 15 \\
\hline 3780 & 195 & 1 & - & - & الضباط & 16 \\
\hline 8779 & 174 & 1 & - & - & الزاوية & 17 \\
\hline 22392 & 274 & 1 & - & - & الثرقية & 18 \\
\hline 7571 & 258 & 1 & - & - & الزهراء & 19 \\
\hline 37810 & 290 & 1 & - & - & الثهاءو & 20 \\
\hline 310642 & 8276 & 42 & - & - & المجموع & \\
\hline
\end{tabular}

المصدر : المديرية العامة لتربية محافظة ذي قار رقم التخطيط ، بيانات غير منشورة 
المجلة الحولية اللملور اللأسانية والإمتماعية International Journal of Humanities and Social Sciences website:www.ijohss.com Email:editor@ijohss.com ISSN: $2415-4822$
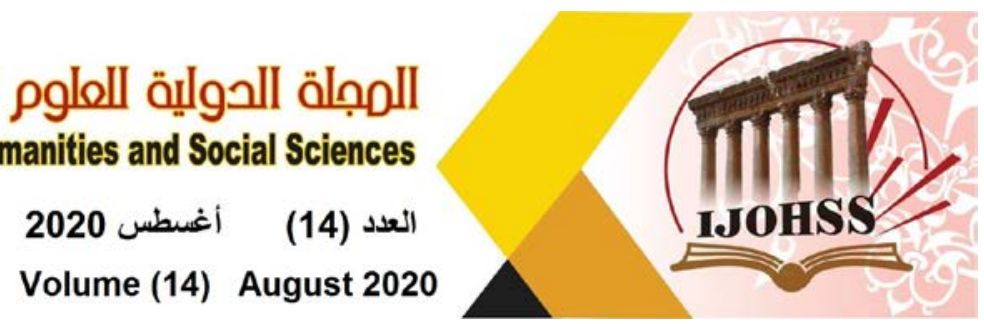

$$
\text { خريطة رقم (3) التوزيع المكاني للمدارس الابتدائية الأهلية في مدينة الناصرية }
$$

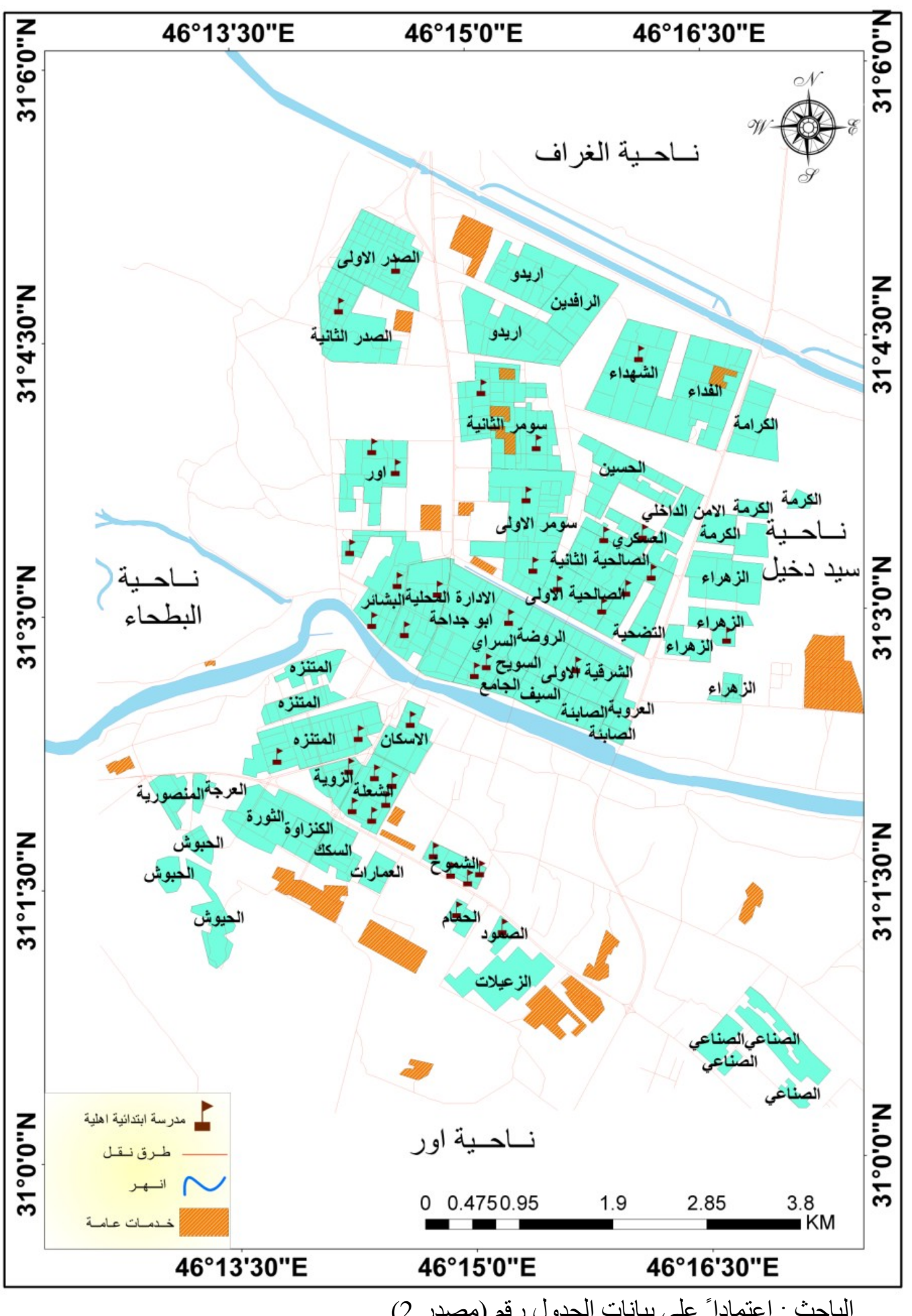


المجلة الدولية اللعلوم الأنسانية والإمتهاعية International Journal of Humanities and Social Sciences website:www.ijohss.com Email:editor@ijohss.com العدد (14) أغسطس 2020 ISSN: $2415-4822$

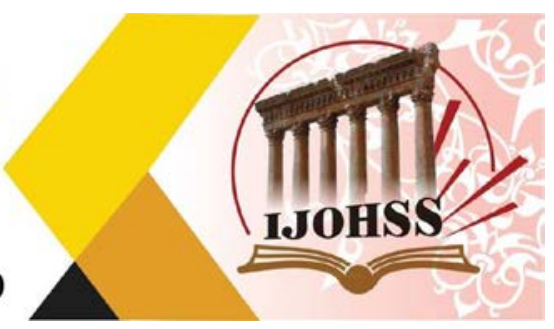

شكل رقم (2) اعداد التناميذ في مدارس التعليم الابتدائي الاهلي في مدينة الناصرية

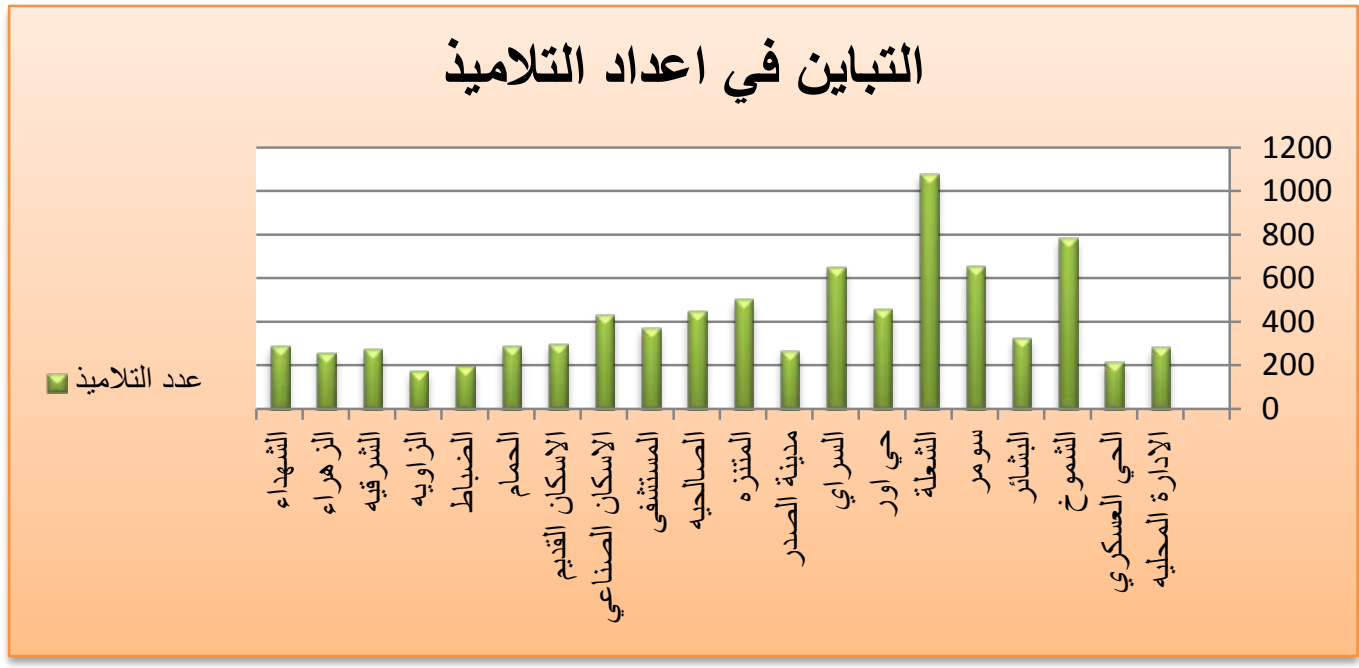

المصدر : الباحث اعتمادا" على بيانات الجدول رقم (2)

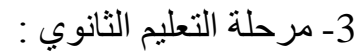

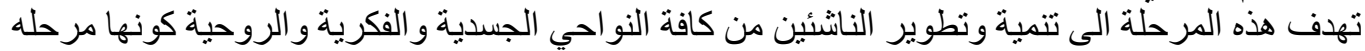

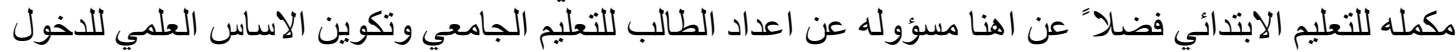

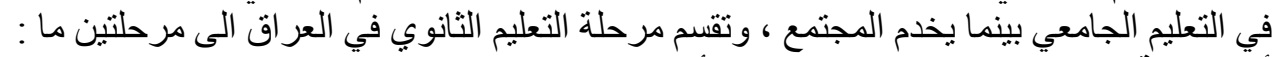

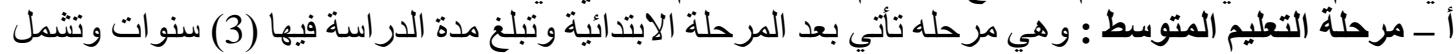

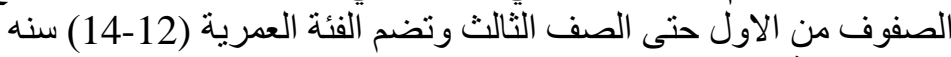

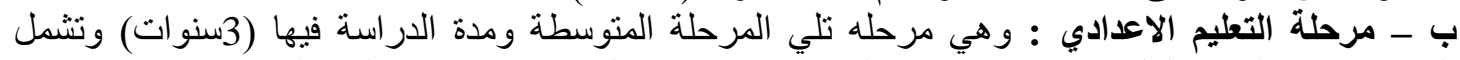

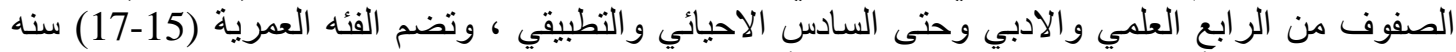

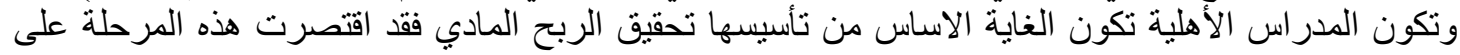
المدر اس الثانوية و التي تضم الصفوف من الاول المتوسط حتى السادس الاعدادي ومن خلال الجدول رقم ( 3 التادية )

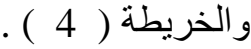

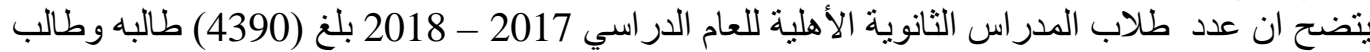

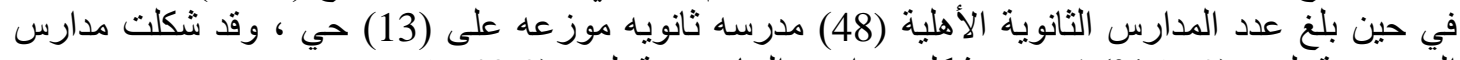

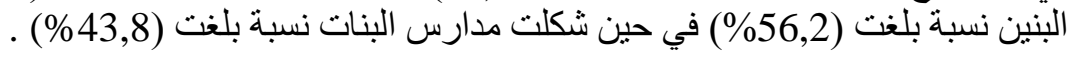

التوزيع الجغرافي لمدارس التعليم الثانوي الاهلي في مدينة الناصرية :

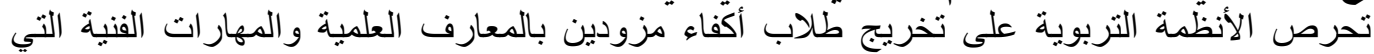

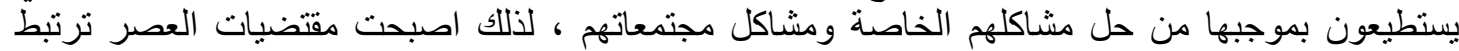
ارتباط كبير ا" بمجمو عه المهارات التي بتطلبها العمل الذي يعد لهُ المتعلم ، في اطار من المرونة تسمح لله

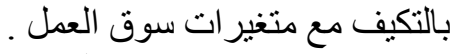

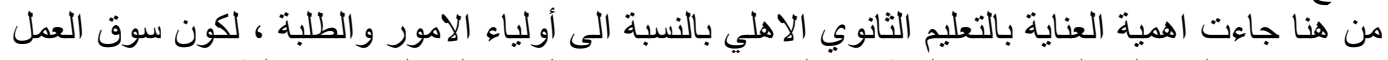

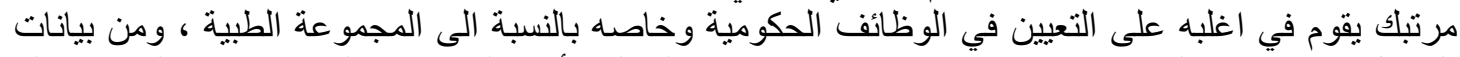

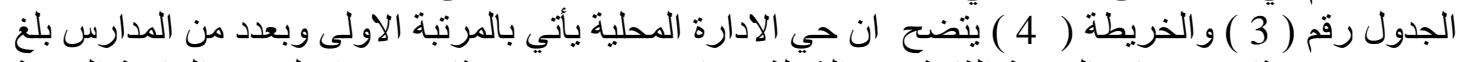

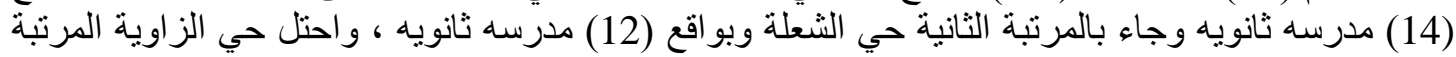

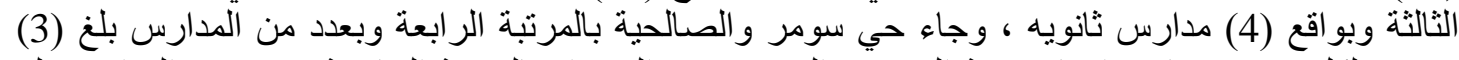

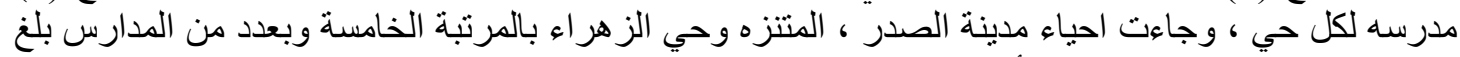

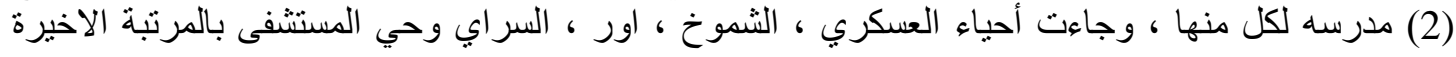




\section{المجلة الحولية اللهلور الآسسانية والإمتماعية}

International Journal of Humanities and Social Sciences

website:www.ijohss.com

Email:editor@ijohss.com

العدد (14) أغطط 2020

IJOHSS

ISSN: 2415 - 4822

Volume (14) August 2020

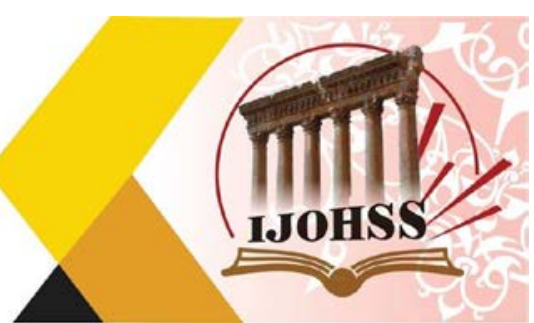

وبو اقع (1) مدرسة ثانوية لكل منها في حين انعدم وجود المدارس الثانوية الأهلية في بقية احياء مدينة الناصرية

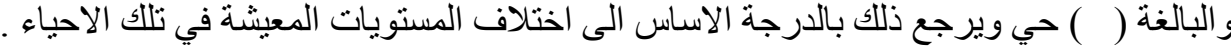

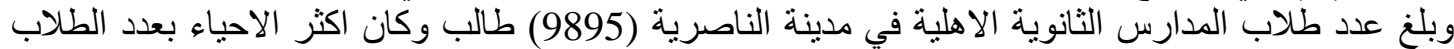

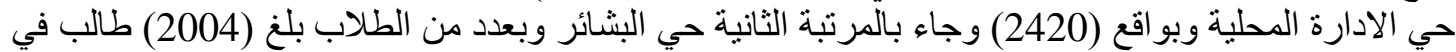

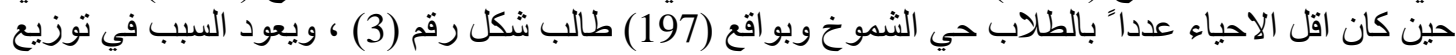

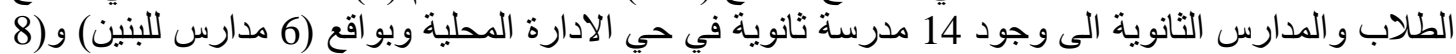

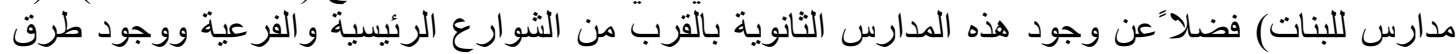

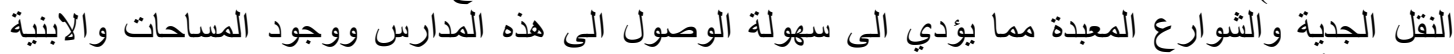

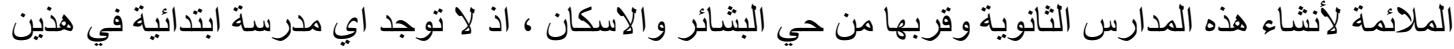

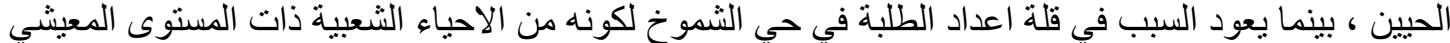

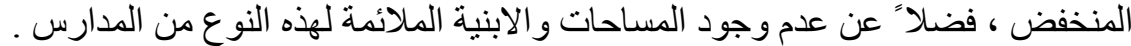

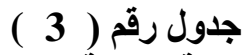

التوزيع المكاني للمدارس الثانوية الاهلية وعدد الطلاب في مدينة الناصرية

\begin{tabular}{|c|c|c|c|c|c|c|c|c|}
\hline \multirow[t]{2}{*}{ علد السكان } & \multicolumn{3}{|c|}{ عدد الطلاب } & \multicolumn{3}{|c|}{ عدد المدارس } & \multirow[t]{2}{*}{ الحي او المحــــة } & \multirow[t]{2}{*}{$ت$} \\
\hline & المجموع & اناث & ذكور & المجموع & بنات بن ب & بنين & & \\
\hline 15068 & 2420 & 134 & 1120 & 14 & 8 & 6 & الادارة المحلية & 1 \\
\hline 10660 & 203 & 203 & - & 1 & - & 1 & العسكري & 2 \\
\hline 26965 & 197 & 197 & - & 1 & - & 1 & الثموخ & 3 \\
\hline 41650 & 733 & 405 & 328 & 3 & 1 & 2 & سومر الاولى & 4 \\
\hline 28860 & 2004 & 1022 & 982 & 13 & 6 & 7 & الثطلة & 5 \\
\hline 21902 & 248 & - & 248 & 1 & - & 1 & اور & 6 \\
\hline 9160 & 198 & - & 198 & 1 & - & 1 & السراي & 7 \\
\hline 2977 & 438 & 188 & 250 & 2 & 1 & 1 & مدينة الصدر & 8 \\
\hline 12990 & 593 & 318 & 275 & 2 & 1 & 1 & المتنزه & 9 \\
\hline 11894 & 388 & - & 388 & 1 & - & 1 & المستشفى & 10 \\
\hline 23392 & 677 & 187 & 490 & 4 & 1 & 3 & الزاوية & 11 \\
\hline 7798 & 906 & 501 & 405 & 2 & 1 & 1 & الزهراء & 12 \\
\hline 11894 & 390 & 257 & 133 & 3 & 2 & 1 & |الصالحية & 13 \\
\hline 225210 & 9395 & 4178 & 5217 & 48 & 21 & 27 & المجموع & \\
\hline
\end{tabular}

المصدر : المديرية العامة بتربية محافظة ذي قار ، قسم التخطيط ، بيانات غير منشورة 
المجلة الحولية اللعلوم اللأسانية والإمتماعية International Journal of Humanities and Social Sciences website:www.ijohss.com Email:editor@ijohss.com ISSN: 2415 - 4822
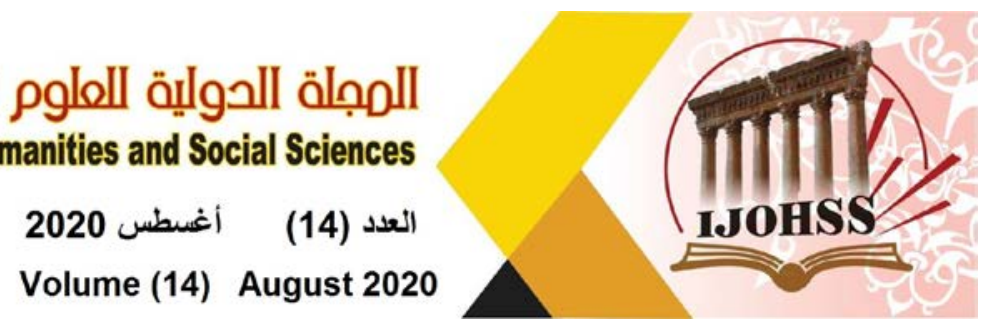

خريطة رقم (4) التوزيع المكاني لمدارس التطليم الثانوي الاهلي في مدينة الناصرية

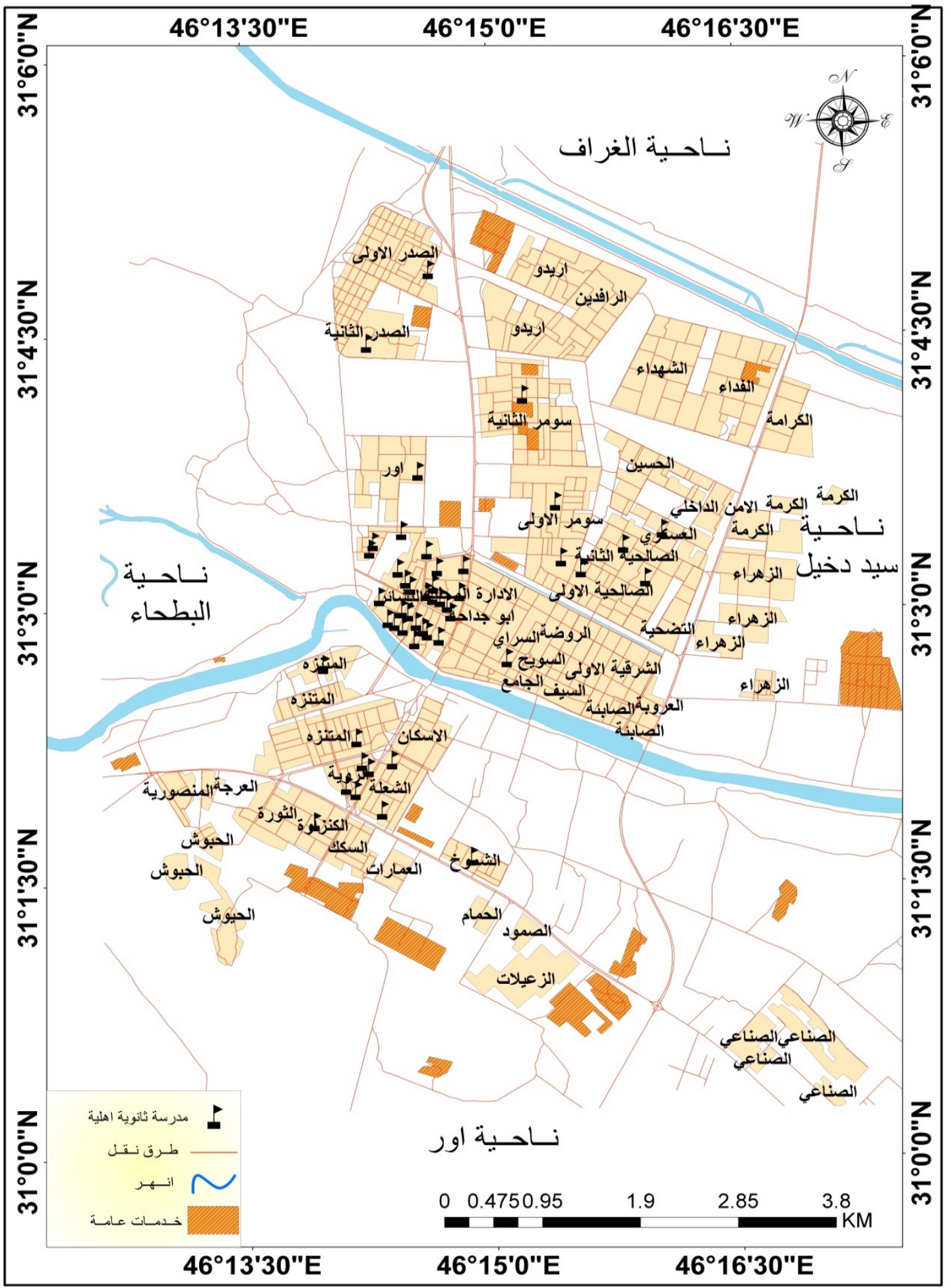

الصددر : الباحث اعتماداء بيانات الجدول رقم (3) 


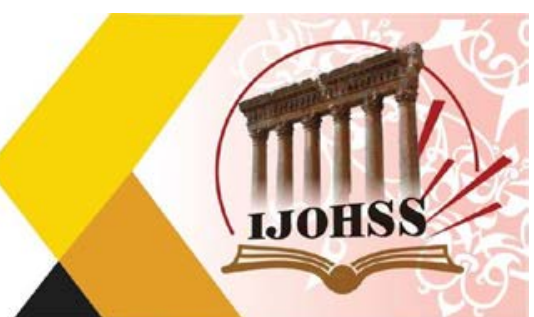

شكل رقم (3) اعداد طلاب المدارس الثانوية الأهلية في مدينة الناصرية

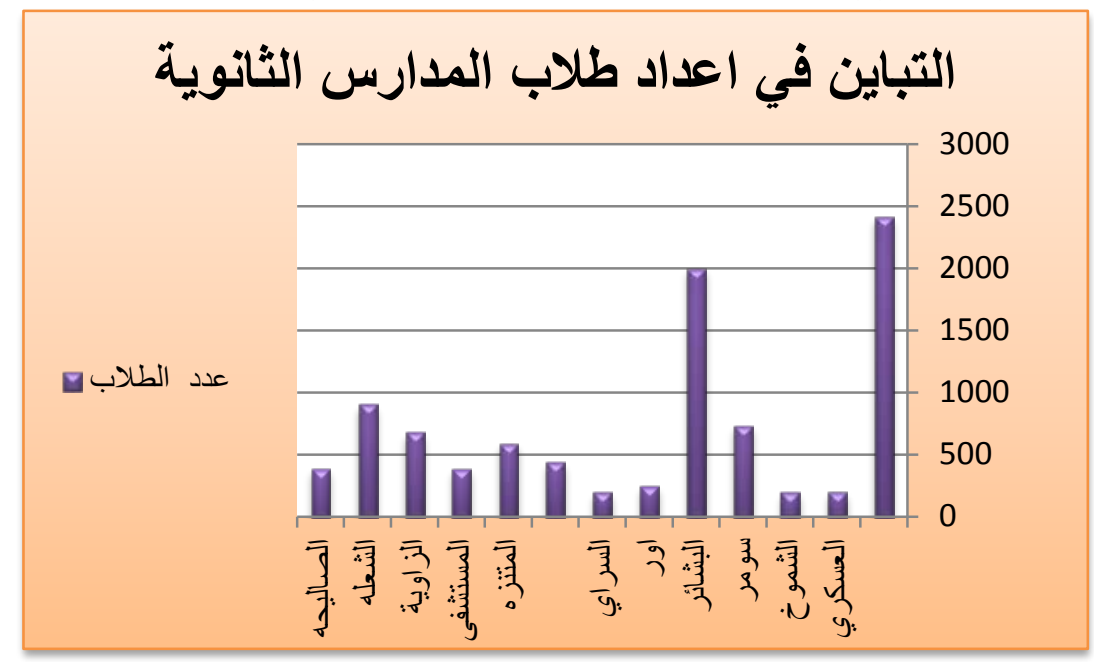

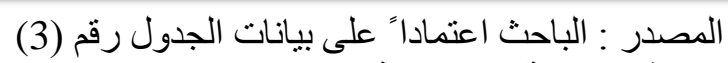

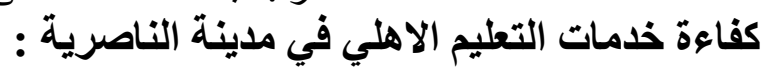

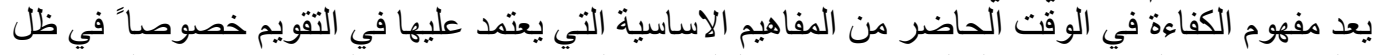

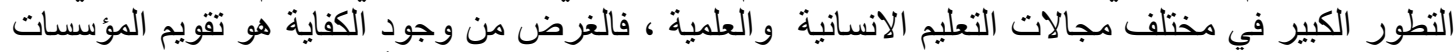

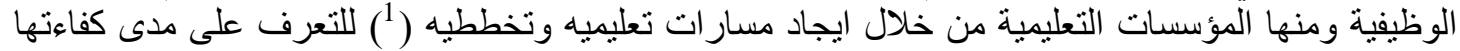

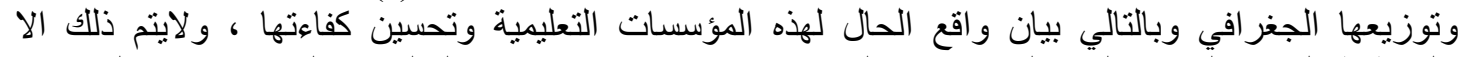

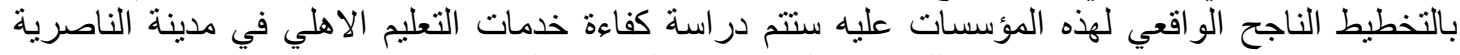

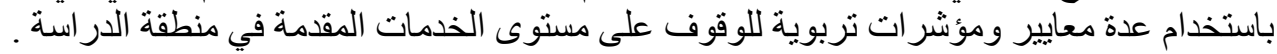
أولاً : مؤشرات ألكثافة الطلابية في مرحلة التعليم الابتدائي

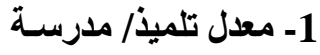

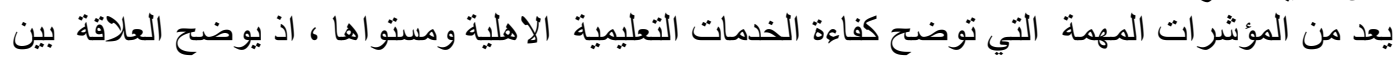

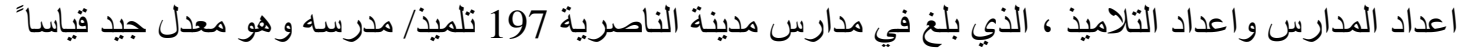

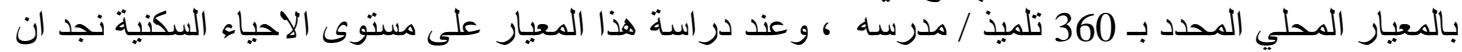
اعلى معدل وصل الى 297 تلميذ/مدرسه جدول رقم

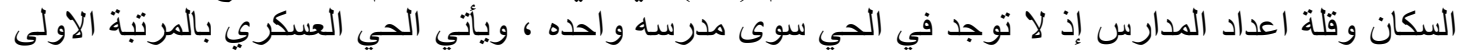

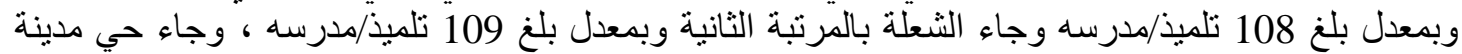

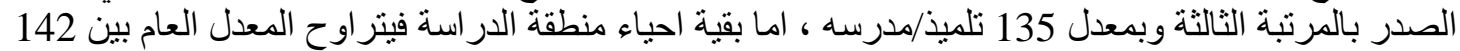

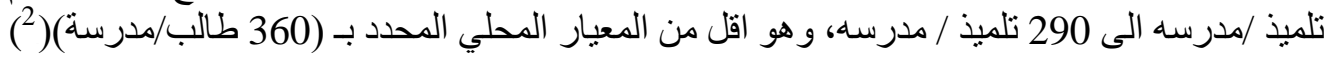

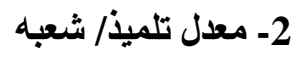

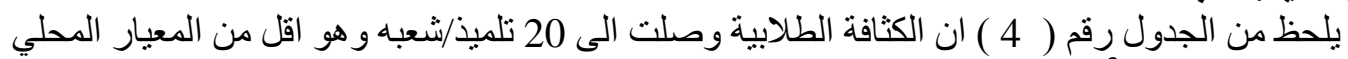

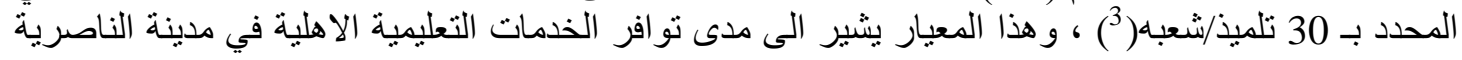

1 - احمد حسن عو اد الدليمي ، التحليل المكاني للذذمات التعليميه في مدينة الرمادي ، اطروحة دكتوراه غير منشورة ،

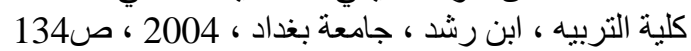
2 - وز ارة التخطيط ، هيئة التخطيط العمر اني ، اعداد وتنفيذ التصاميم الاساسية للمدن ، بغداد ، 1983 ، ص34 3 - المصدر نفسه 


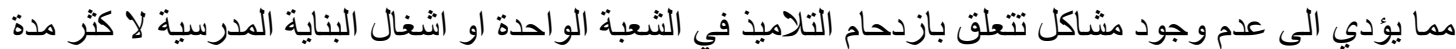

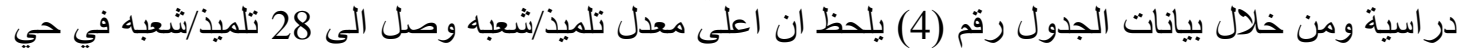

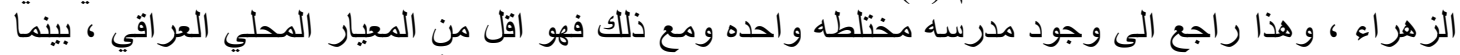

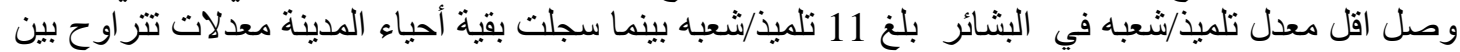

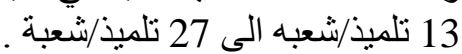

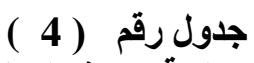

التوزيع المكاني للمدراس الاهلية الابتذائية ومؤشر اتها التربوية في مدينة الناصرية 2018

\begin{tabular}{|c|c|c|c|c|c|c|c|c|}
\hline \multicolumn{3}{|c|}{ مؤشرات تربوية } & \multirow{2}{*}{ عدد } & \multirow{2}{*}{ المعلمين } & \multirow{2}{*}{ التلاميذ } & \multirow{2}{*}{ المدراس } & \multirow{2}{*}{ او الحيحة } & \multirow[t]{2}{*}{ ت } \\
\hline تلميذ/معلم & تلميذ/شعبه & تلميذ/مدرسه & & & & & & \\
\hline 13 & 19 & 142 & 15 & 22 & 285 & 2 & الادارة المحلية & 1 \\
\hline 9 & 13 & 108 & 17 & 24 & 217 & 2 & الحي العكري & 2 \\
\hline 19 & 23 & 197 & 34 & 42 & 290 & 4 & الثموخ & 3 \\
\hline 12 & 11 & 109 & 29 & 27 & 927 & 3 & البشائر & 4 \\
\hline 14 & 16 & 164 & 40 & 46 & 656 & 4 & سومر & 5 \\
\hline 15 & 22 & 216 & 50 & 74 & 1058 & 5 & الالشعلة & 6 \\
\hline 16 & 25 & 228 & 18 & 29 & 457 & 2 & حي اور & 7 \\
\hline 14 & 27 & 217 & 24 & 45 & 650 & 3 & السراي & 8 \\
\hline 13 & 18 & 135 & 15 & 20 & 271 & 2 & مدينة الصدر & 9 \\
\hline 19 & 26 & 252 & 19 & 27 & 504 & 2 & المتتزه & 10 \\
\hline 13 & 18 & 224 & 25 & 34 & 448 & 2 & الصالحيه & 11 \\
\hline 12 & 25 & 187 & 15 & 30 & 375 & 2 & المستشفى & 12 \\
\hline 15 & 21 & 218 & 21 & 29 & 437 & 2 & الإنكاعي & 13 \\
\hline 17 & 18 & 297 & 20 & 17 & 297 & 1 & الاسكان القديم & 14 \\
\hline 16 & 19 & 289 & 15 & 18 & 289 & 1 & الحمام & 15 \\
\hline 13 & 19 & 195 & 10 & 15 & 195 & 1 & الضباط & 16 \\
\hline 11 & 17 & 174 & 10 & 16 & 174 & 1 & الزاوية & 17 \\
\hline 19 & 27 & 274 & 10 & 14 & 274 & 1 & الثرقية & 18 \\
\hline 12 & 28 & 258 & 9 & 21 & 258 & 1 & الزهراء & 19 \\
\hline 15 & 26 & 290 & 11 & 9 & 290 & 1 & الشهـاء & 20 \\
\hline 15 & 20 & 197 & 407 & 569 & 8276 & 42 & المجموع & \\
\hline
\end{tabular}

المصدر : المديرية العامة لتربية محافظة ذي قار ، قسم التخطيط للعام الدراسي 2017-2018 بيانات غير منشورة 3- تلمبذ/معلم : المديرئ 


\title{
المجلة اللدولية اللملوم الأسانية والإمتصاعية
} International Journal of Humanities and Social Sciences website:www.ijohss.com Email:editor@ijohss.com ISSN: $2415-4822$

\author{
العدد (14) أغطس 2020 \\ Volume (14) August 2020
}

IJOHSS

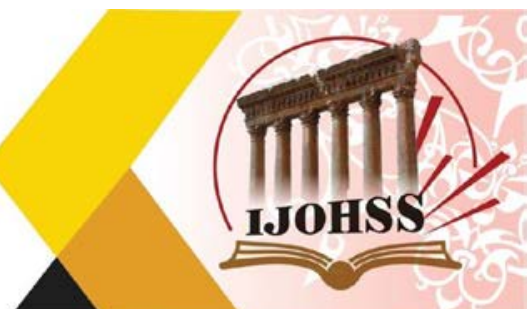

يوضح هذا المؤشر العلاقة بين اعداد المعلمين من جهة واعداد التلاميذ من جهة اخرى ، وإن إذ يعد من

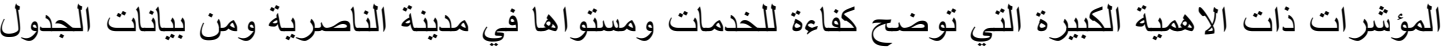

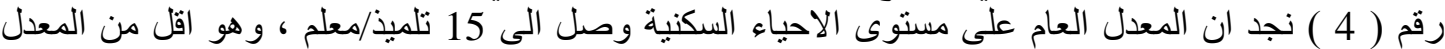

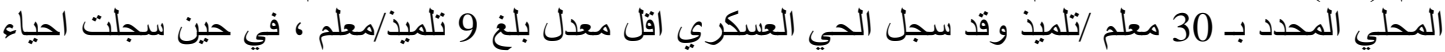

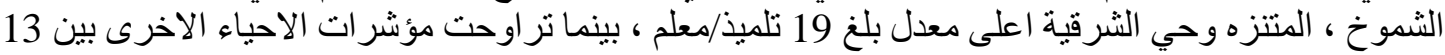

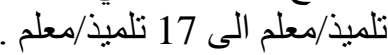
ثانيـاً : مؤشرات الكثافة الطلابية لمرحلة التعلم الثانوي

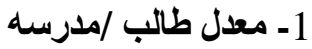

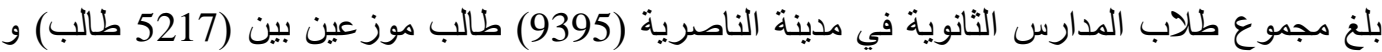

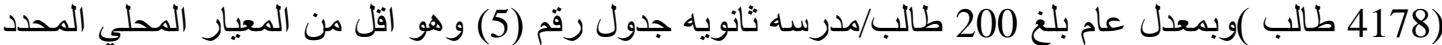

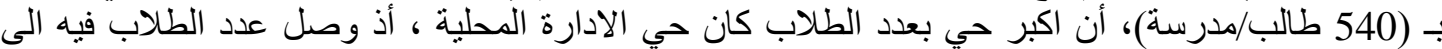

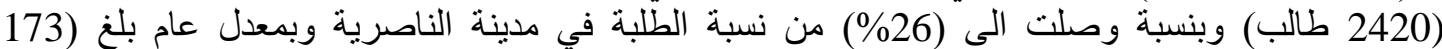

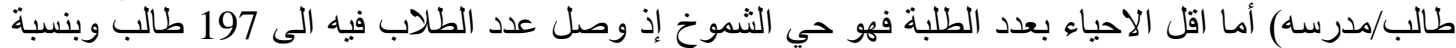

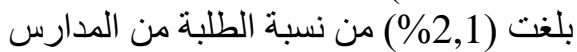
2- 2 - معدل طالب /شعبه

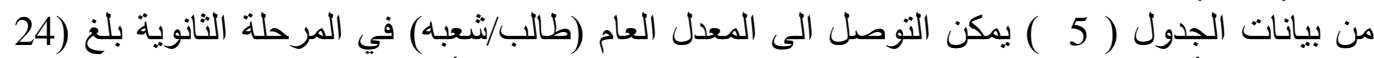

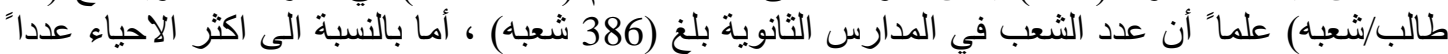

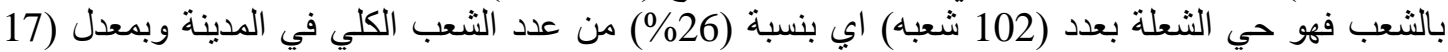

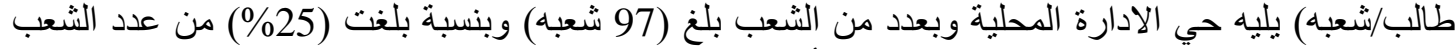

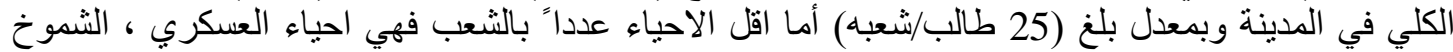
وحي السر اي بعدد بلغ (10شعب) لكل حي اي بنسبة بلغت (2,5\%) من عدد الشعب الكلي في المدينة .

جدول رقم ( 5 ) التوزيع المكاني للمدارس الاهلية الثانوية ومؤشراتها التربوية في مدينة الناصرية 2018

\begin{tabular}{|c|c|c|c|c|c|c|c|c|}
\hline \multicolumn{3}{|c|}{ مؤشرات تربوية } & \multirow{2}{*}{ الشعب } & \multirow{2}{*}{ المدرسين } & \multirow{2}{*}{ الطلاب } & \multirow{2}{*}{ المدارس } & \multirow{2}{*}{ والمحئة } & \multirow[t]{2}{*}{ ت } \\
\hline مدرس/طالب & شعبه/طالب & مدرس/طالب & & & & & & \\
\hline 9 & 25 & 173 & 97 & 275 & 2420 & 14 & الالدارة & 1 \\
\hline 7 & 20 & 203 & 10 & 29 & 203 & 1 & العسكري & 2 \\
\hline 10 & 20 & 197 & 10 & 20 & 197 & 1 & الشموخ & 3 \\
\hline 17 & 25 & 244 & 29 & 42 & 733 & 3 & سومر & 4 \\
\hline 8 & 17 & 154 & 102 & 260 & 2004 & 13 & الشعلة & 5 \\
\hline 13 & 21 & 248 & 12 & 19 & 248 & 1 & اور & 6 \\
\hline 11 & 13 & 198 & 10 & 21 & 198 & 1 & السراي & 7 \\
\hline 9 & 19 & 219 & 13 & 23 & 438 & 2 & مدينة & 8 \\
\hline 11 & 26 & 297 & 23 & 55 & 593 & 2 & المتتزه & 9 \\
\hline 9 & 28 & 388 & 14 & 44 & 388 & 1 & المستشفى & 10 \\
\hline 9 & 20 & 169 & 33 & 72 & 677 & 4 & الزاوية & 11 \\
\hline 12 & 23 & 453 & 40 & 74 & 906 & 2 & الثرقية & 12 \\
\hline 9 & 23 & 130 & 17 & 42 & 390 & 3 & الصالحية & 13 \\
\hline 10 & 24 & 200 & 386 & 979 & 9395 & 48 & المجموع & \\
\hline
\end{tabular}

المصدر : المديرية العامة لتربية محافظة ذي قار ، قسم التخطيط للعام الدراسي 2017 - 201 


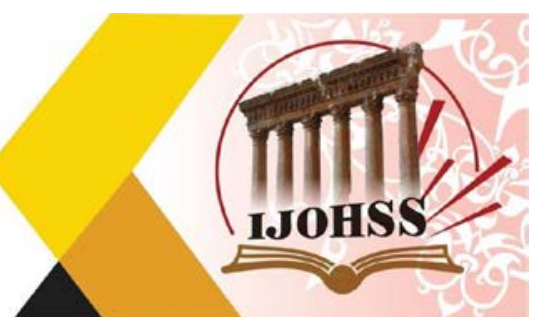

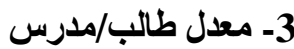

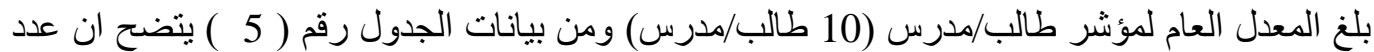

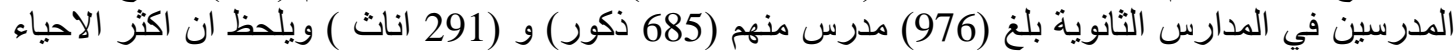

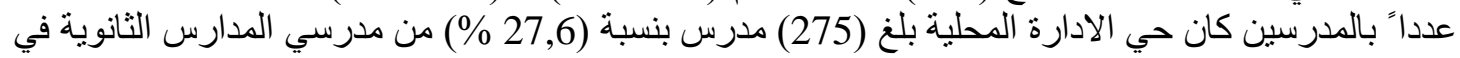

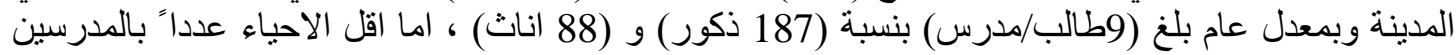

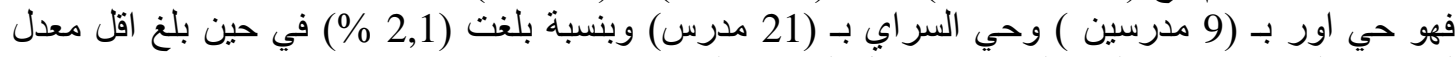

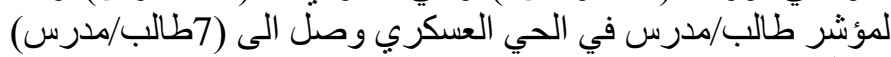

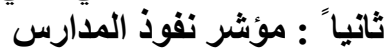

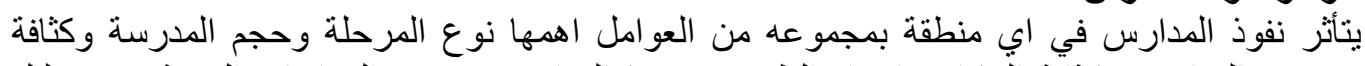

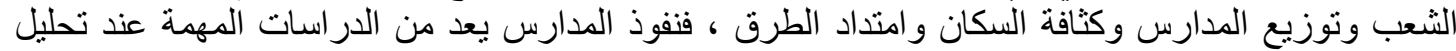

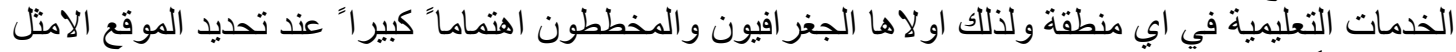

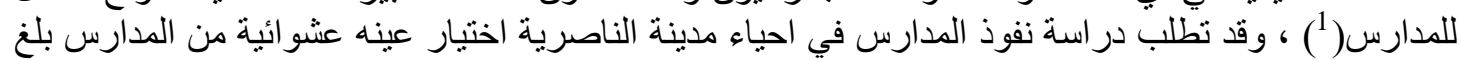

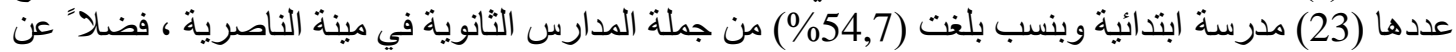

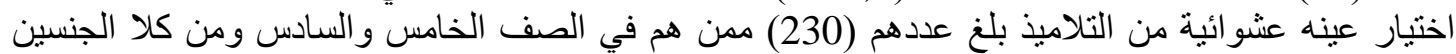

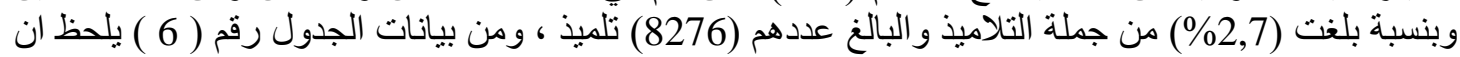

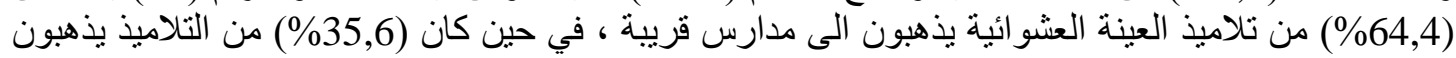

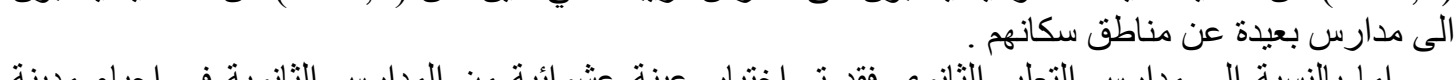
اما بالنسبة الى مدارس التعليم الثنانوي فقد تم اختيار عينة عثوائية ائية من المدارس الثانوية في احياء مدينة

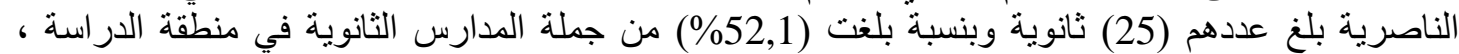

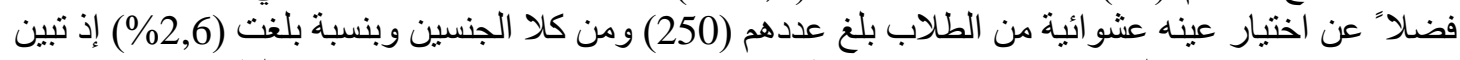
ان (42,4\%) يذهبون الى مدارس قريبة من مناطق سكانهم ، في حين اكد (57,7\%) من الطناب الطناب انهم يذهبون

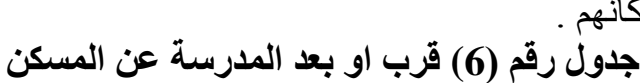
الى مدارس بعيدة عن مناطق سكانهم .

\begin{tabular}{|c|c|c|c|c|c|c|c|c|c|c|}
\hline \multirow[t]{2}{*}{ العينة } & & \multicolumn{3}{|c|}{ طلاب المدارس الثانوية الاهلية } & \multirow{2}{*}{ العينة } & \multicolumn{4}{|c|}{ تلاميذ المدارس الابتدائية الاهلية } & البيانات \\
\hline & $\%$ & الملاب مدارس بذبون & $\%$ & ثذاربون الى & & & 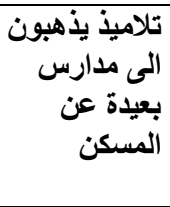 & $\%$ & 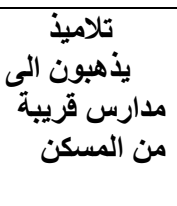 & \\
\hline 250 & 57,6 & 144 & 42,4 & 106 & 230 & 35,6 & 82 & 64,4 & 148 & الناصرية \\
\hline 250 & 57,6 & 144 & 42,4 & 106 & 230 & 35,6 & 82 & 64,4 & 148 & المجموع \\
\hline
\end{tabular}

المصدر : الاراسة الميدانية 2018

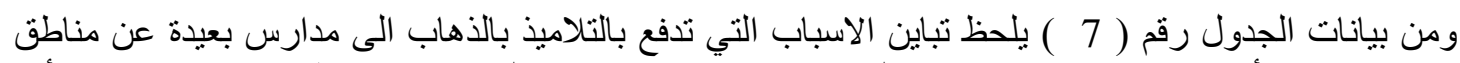

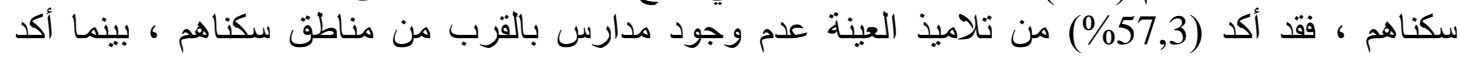

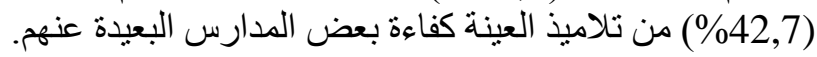

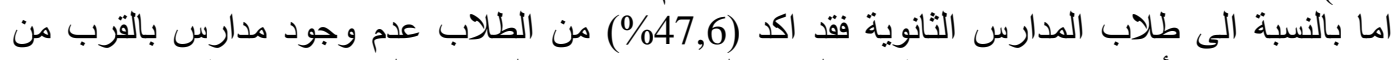

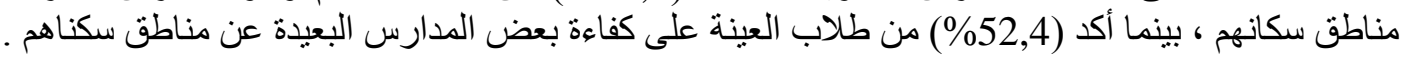

1 - طاهر جمعه طاهر يوسف ، التحليل المكاني للخدمات التعليمية في مدينة نابلس ، رسالة ماجستير غير منشورة ، كلية الدراسات العليا ، جامعة النجاح ، فلسطين ، 2007 ، ص64 للئل 
المجلة اللدولية اللملوم الأسانية والإمتصاعية

International Journal of Humanities and Social Sciences

website:www.ijohss.com

Email:editor@ijohss.com

أغطس 2020

العدد (14)

Volume (14) August 2020

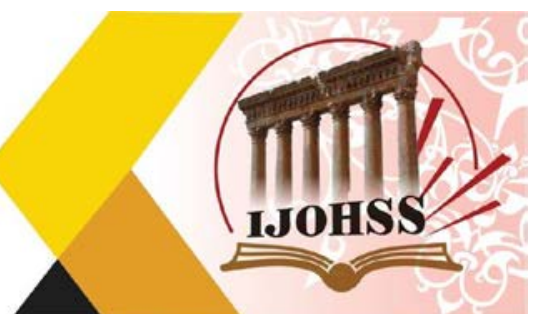

ISSN: 2415 - 4822

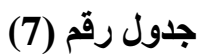

سبب التحاق التلاميذ والطلاب بالمدارس البعيدة عن مساكنهم في مدينة الناصرية

\begin{tabular}{|c|c|c|c|c|c|c|c|c|c|c|c|}
\hline \multirow[t]{2}{*}{ العينة } & & \multicolumn{3}{|c|}{ طلاب المدارس الثانوية } & \multirow[t]{2}{*}{ العينة } & \multicolumn{5}{|c|}{ تلاميذ المدارس الابتدائية الاهلية } & | ل البيانات \\
\hline & $\%$ & المفاءة المسيدة عن & $\%$ & 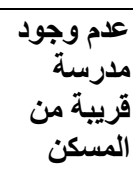 & & $\%$ & البعايدة المبكن & العينة & $\%$ & مدرسة قريبة & \\
\hline 250 & 52,4 & 131 & 47,6 & 119 & 230 & 42,7 & 98 & 230 & 57,3 & 132 & ماينة \\
\hline 250 & 52,4 & 131 & 47,6 & 119 & 230 & 42,7 & 98 & 230 & 57,3 & 132 & المجموع \\
\hline
\end{tabular}

المصدر : الدراسة الميدانية 2018

العوامل المؤثرة على امتداد نفوذ المدارس في مدينة الناصرية :

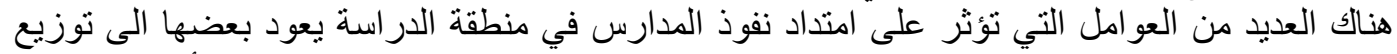

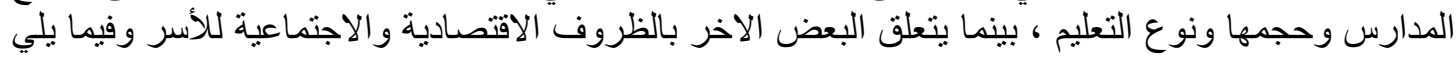

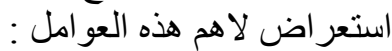

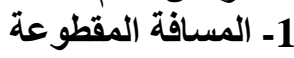

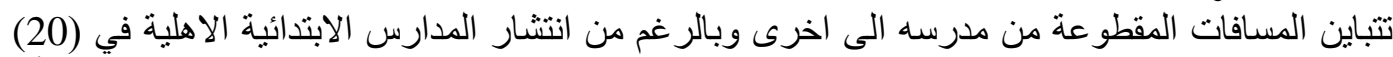

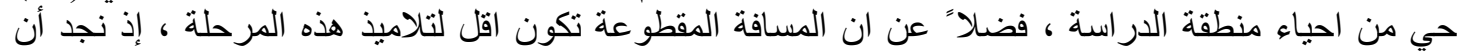

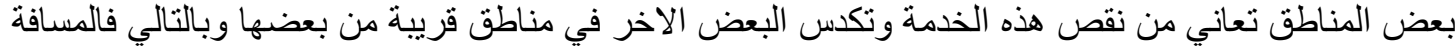

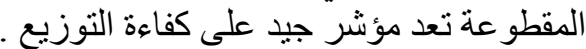

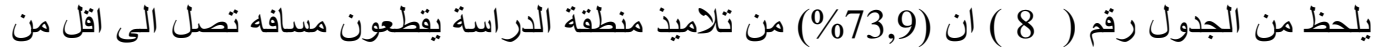

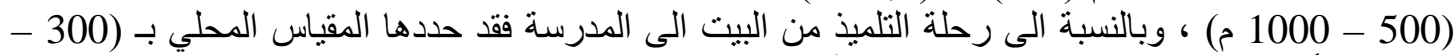

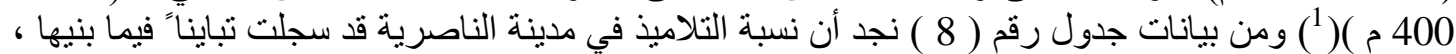

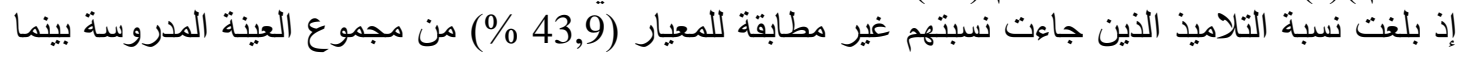

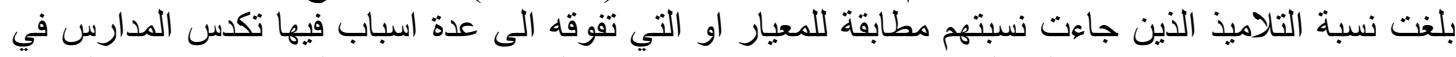

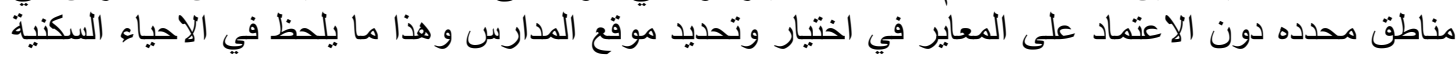

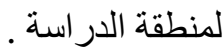

اما بالنسبة الى طلاب المدارس الثانوية فيلحظ من بيانات الجدول رقم ( 8 ) ، أن نسبة الطلاب في العينة

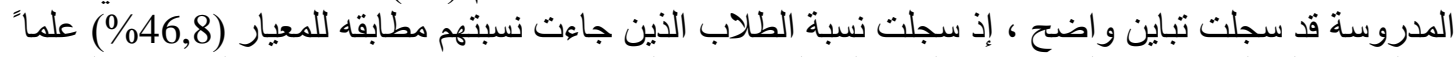

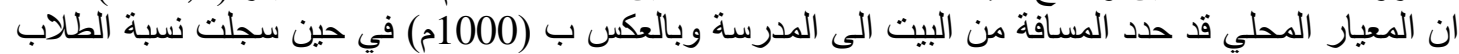

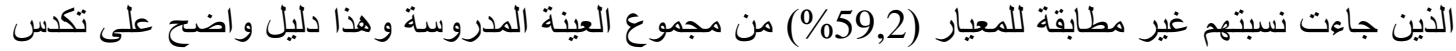

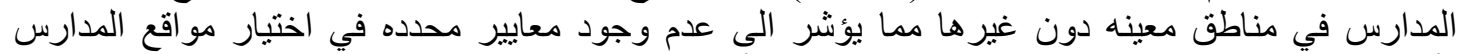

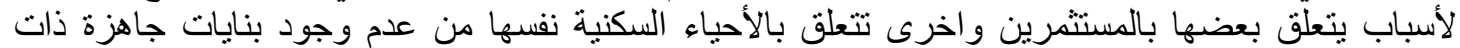

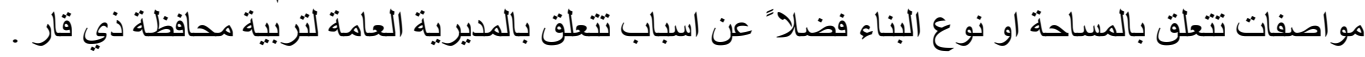

1 - وزارة التخطيط ، قسم الاسكان و المستوطنات السكنية ، هيئة التخطيط الاقليمية اسس ومعايير مباني الخدمات ، بغداد ،

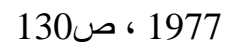


المجلة اللحولية اللملوم الآسسانية والإمتصاعية

International Journal of Humanities and Social Sciences

website:www.ijohss.com

Email:editor@ijohss.com

أغسطس 2020

العدد (14)

IJOHSS

ISSN: $2415-4822$

Volume (14) August 2020

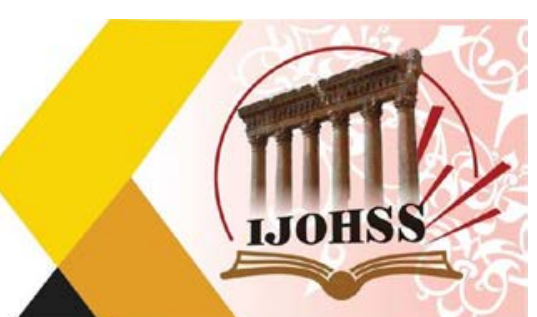

جدول رقم (8) المسافة المقطوعة لتلاميذ وطلاب المدارس الثانوية الاهلية من مدينة الناصرية 2000 الامية

\begin{tabular}{|c|c|c|c|c|c|c|c|c|c|c|c|c|}
\hline العينة & اكثر من 3000 & $\begin{array}{r}-2000 \\
3000\end{array}$ & $\begin{array}{r}-1000 \\
2000\end{array}$ & $\begin{array}{r}-500 \\
1000\end{array}$ & اقل من & العينة & 300 300م من & $\begin{array}{r}-2000 \\
3000\end{array}$ & $\begin{array}{r}-1000 \\
2000\end{array}$ & $\begin{array}{r}-500 \\
1000\end{array}$ & اقل من 500 م & الادارية \\
\hline 250 & 5 & 10 & 35 & 70 & 130 & 230 & 10 & 20 & 30 & 69 & 101 & الناصرينة \\
\hline 250 & 5 & 10 & 35 & 70 & 130 & 230 & 10 & 20 & 30 & 69 & 101 & المجموع \\
\hline
\end{tabular}

المصدر : الدراسة الميدانية 2018

2- 2 2 وسيلة النقل المستخدمة :

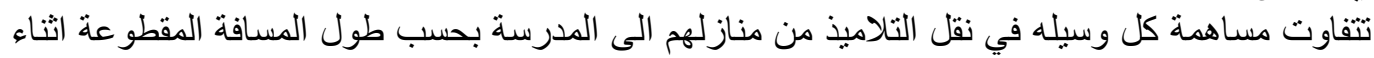

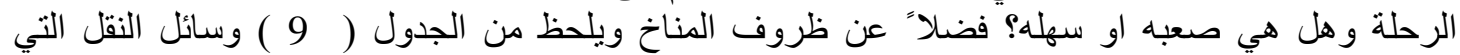

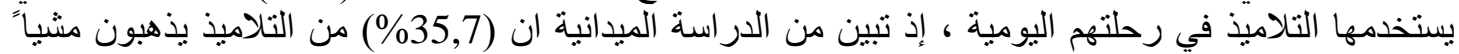

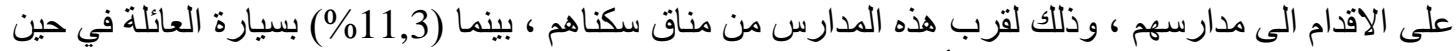

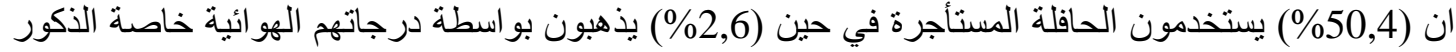

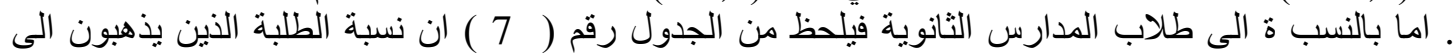

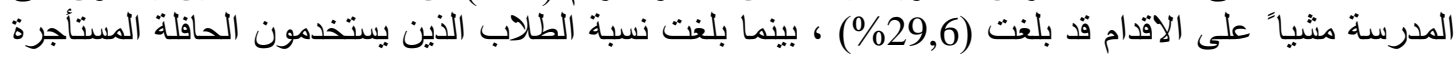

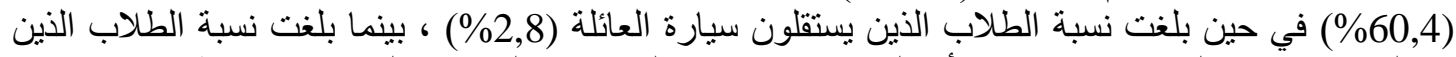

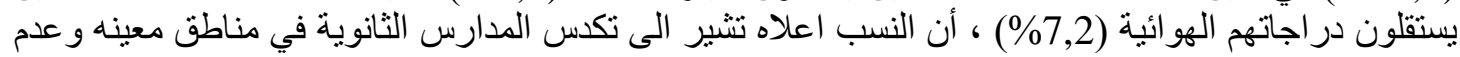

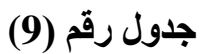
توزيعها بشكل عادل بين الاحياء

وسائل النقل المستخدمة في رحلة التلاميذ والطلاب في المدارس الاهلية في مدينة الناصرية

\begin{tabular}{|c|c|c|c|c|c|c|c|c|c|c|c|c|c|c|c|c|c|c|}
\hline العينة اليّ & & الهواج & & خاصة & & سيازة & & مشياً الاقداً & الجمالية & & هوائية & & خاصةًة & & سيارة & & مشياً & الادارية \\
\hline & $\%$ & الـ العد & $\%$ & العدد & $\%$ & العدد & $\%$ & العدد & & $\%$ & العدد & $\%$ & العدد & $\%$ & العدد & $\%$ & العدد & \\
\hline 250 & 7,2 & 18 & 3,5 & 7 & 60,4 & 151 & 29,6 & 74 & 230 & 2,6 & 5 & 11,3 & 26 & 50,4 & 116 & 35,7 & 83 & مداينة \\
\hline 250 & 7,2 & 18 & 3,5 & 7 & 60,4 & 151 & 29,6 & 74 & 230 & 2,6 & 5 & 11,3 & 26 & 50,4 & 116 & 35,7 & 83 & المجموع \\
\hline
\end{tabular}

المصدر : الارسة الميدانية 2018

3- الزمن المستغرق في الرحلة المدرسية:

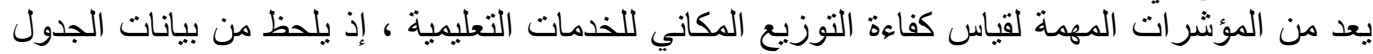

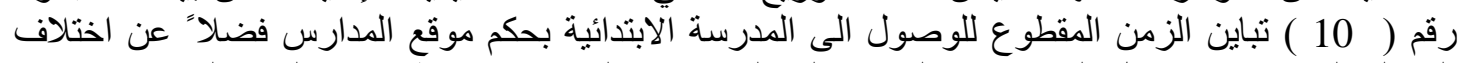

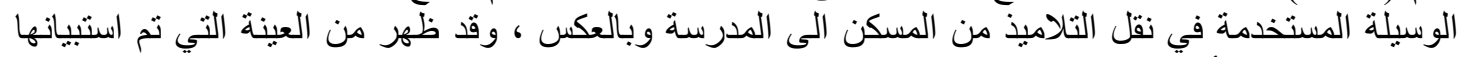

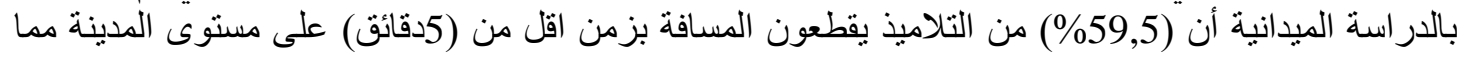

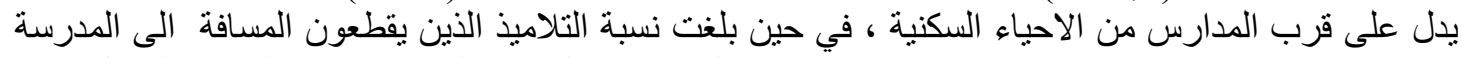

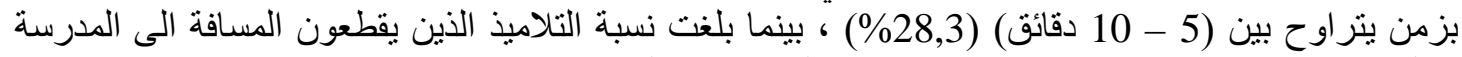
وبالعكس بزمن اكثر من (10 دقائق) (12,2\%) (12\%) على مستوى المدينة .

أن نسبة التلاميذ في مدينة الناصرية التي أوجدت تطابق الحالة مع المعيار المحلي المحدد بـ(5-10 دقائق)

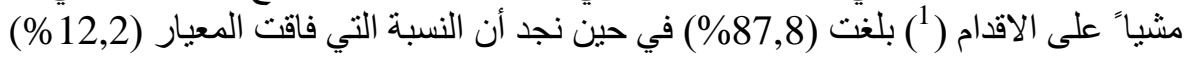

1 - جمهورية العر اق ، وزارة التخطبط ، معاير تخطيط الاسكان لعام 1998 ، ص88 


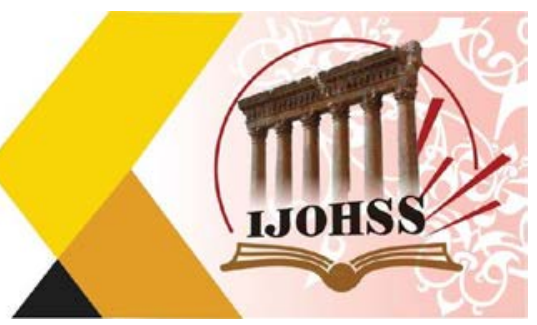

اما بالنسبة الى طلاب المرحلة الثانوية فيلحظ من بيانات الجدول رقم ( 8 ) ) أن (10,7\%) من طلاب العينة

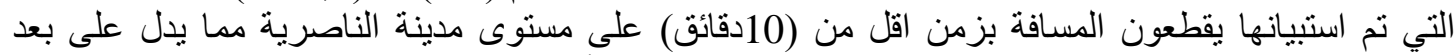

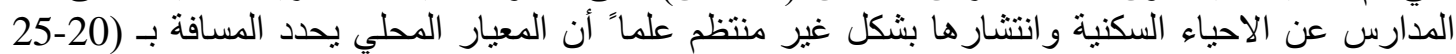

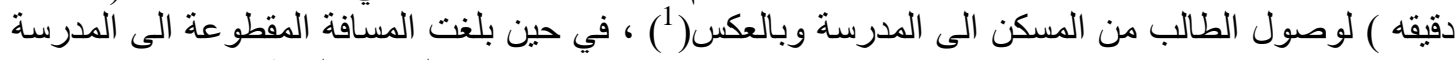

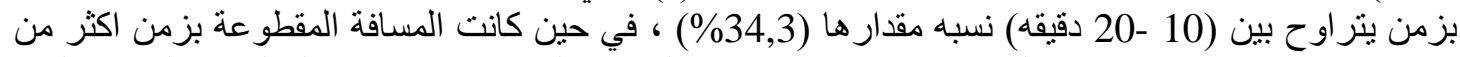

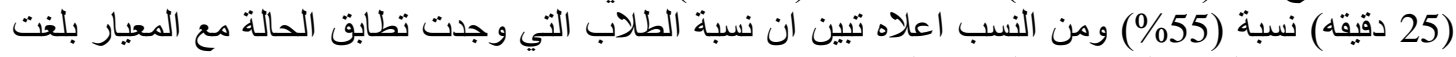

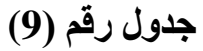

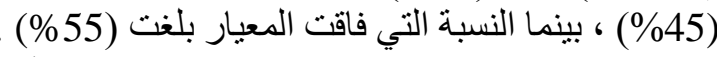

وسائل النقل المستخدمة في رحلة التلاميذ والطلاب في المدارس الاهلية في مدينة الناصرية

\begin{tabular}{|c|c|c|c|c|c|c|c|c|c|c|c|c|c|c|}
\hline \multirow[t]{2}{*}{ الجمالية } & \multicolumn{2}{|c|}{ اكثر من دقيقة 25} & \multicolumn{2}{|c|}{$\begin{array}{c}20-15 \\
\text { دقيقة }\end{array}$} & \multicolumn{2}{|c|}{ اقلّ من 15} & \multirow[t]{2}{*}{ العينةً } & \multicolumn{2}{|c|}{ اكثر من 10} & \multicolumn{2}{|c|}{ دقائق 10 -5 } & \multicolumn{2}{|c|}{ اقلّ من 5} & \multirow[t]{2}{*}{ الادارية } \\
\hline & $\%$ & العدد & $\%$ & العدد & $\%$ & العدد & & $\%$ & العدد & $\%$ & العدد & $\%$ & العدد & \\
\hline 250 & 55 & 137 & 34,3 & 86 & 10,7 & 27 & 230 & 12,2 & 28 & 28,3 & 65 & 59,5 & 137 & مدينة \\
\hline 250 & 3,5 & 7 & 60,4 & 151 & 29,6 & 74 & 230 & 2,6 & 5 & 50,4 & 116 & 35,7 & 83 & المجموع \\
\hline
\end{tabular}

المصدر : الاراسة الميدانية 2018

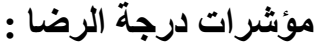

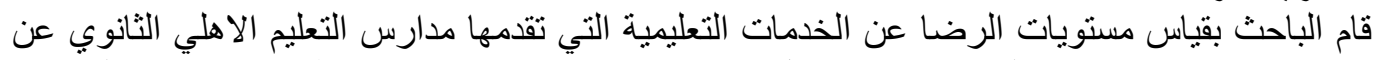

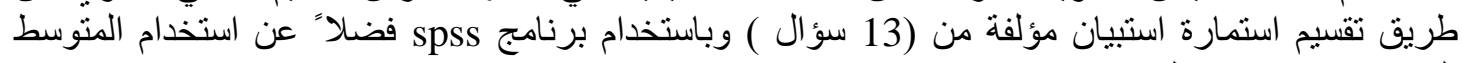

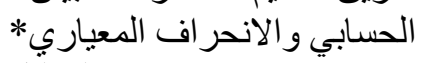
حيث تم استخدام التحليل الاحصيائي لمدينة الناصرية من خلافل (250) استمارة لطلاب التعليم الثانوي

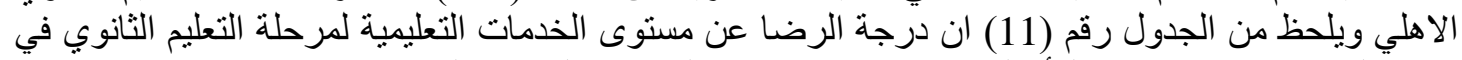

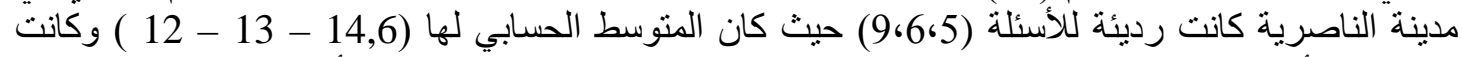

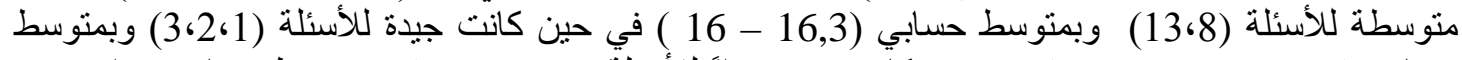

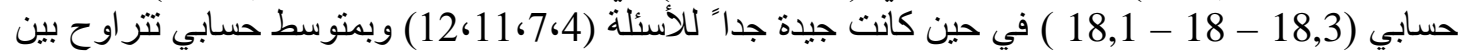
$(18,7-18,6)$

وبناء على ما تقدم يمكن القول ان هناك تبايناً واضحاً في مسنويات كفاءة مؤسسات التعليم الثنانوي الاهلي التهاتي

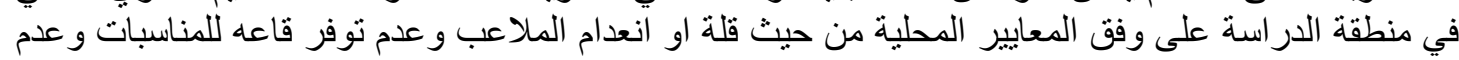

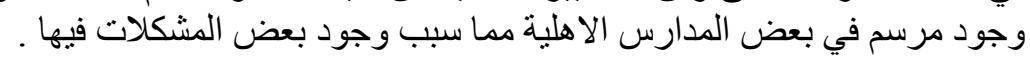




\section{المجلة الدولية اللهلوم الأنسانية والإمتاعية} International Journal of Humanities and Social Sciences website:www.ijohss.com Email:editor@ijohss.com العدد (14) أغططس 2020 IJOHSS ISSN: $2415-4822$

\section{Volume (14) August 2020}

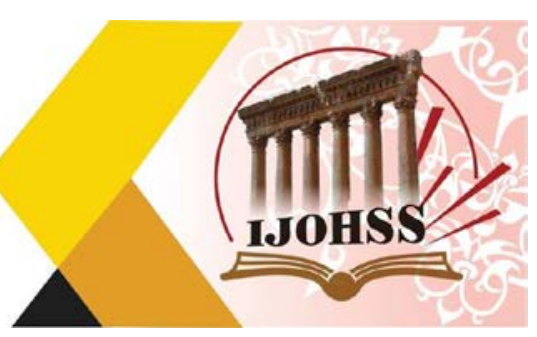

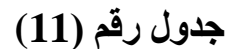

المتوسطات الحسابية والاتحر افات المعيارية ودرجة الرضا عن مستوى الخدمات التعليمية الثانوية الاهلية في مدينة الناصرية لعام العية عن 2018

\begin{tabular}{|c|c|c|c|c|}
\hline درجة الرضـاث & الانحراف المعياري & الحستابي & الســــــــــــال & 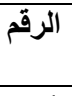 \\
\hline جيده & 2,7 & 18,3 & هل انت راضي عن معاملة مدرسك & 1 \\
\hline جيده & 2,4 & 18 & هل انت راضي عن فترة دوامك في المدرسة & 2 \\
\hline جيده & 2,5 & 18,1 & هل انت راضي عن دورات المياه الصحة في مدرستكك & 3 \\
\hline جيد جذاً & 2,9 & 18,6 & هل انت راضي عن ابنية المدرسة & 4 \\
\hline رديئة & 1,5 & 14,6 & هل انت راضي عن بعد او قرب المؤسسة التعليمية عن مسكتلك & 5 \\
\hline رديئة & 1,4 & 13 & هل انت راضي عن توفر الملاعب في مدرستك & 6 \\
\hline جيا جدا & 2,9 & 18,6 & هل انت راضي عن توفر خدمات الكهرباء في مدرستك & 7 \\
\hline متوسطة & 1 & 16,3 & هل انت راضي عن توفر المكتبة في المدرسة & 8 \\
\hline رديئة & 2,4 & 12 & هل انت راضي عن توفر قاعه للاحتفالات في مدرستك & 9 \\
\hline رديئة & 0,5 & 14,3 & هل انت راضي عن توفر مرسم في مدرستك & 10 \\
\hline جيد جدا & 3 & 18,7 & هل انت راضي عن توفر اجهزة التبريد والتدفئة في مدرستك & 11 \\
\hline جيد جدا & 2,8 & 18,5 & هل انت راضي عن توفر المياه الصالحة للشرب & 12 \\
\hline 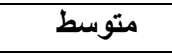 & 5,4 & 16 & هل انت راضي عن توفر الرعاية الصحية في المدرسة & 13 \\
\hline متوسطه & 2,4 & 16,5 & 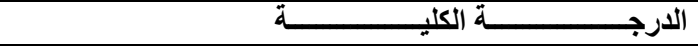 & \\
\hline
\end{tabular}

المصدر : الدر اسة الميدانية لعام 2018

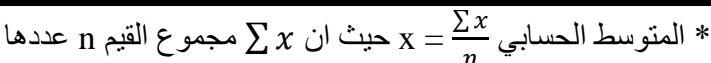

$$
\begin{aligned}
& \text { * الانحر اف المعياري استخدام المعادلة التالية } \\
& \text { للمزيد ينظر }
\end{aligned}
$$

a stowing theomas R.etal satisfaction with medical care (replication )and theoretic reevaiuation on medical care march 1993:pp59 * حيث ان درجات الاستجابة دون(15 رديئة ومن(15 - 17,3 منوسطة)ومن(17,5 - 18,3 جيده)ومن(18,4 18,7 جيده جداء) و اكثر من(18,8 ممتاز)

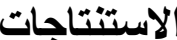

1- ارتبط توزيع مدارس التعليم الاهلي في مدينة الناصرية بتوزيع السكان بصوره مباشره الذي يتباين بين

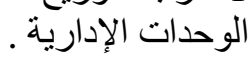

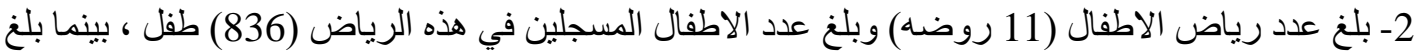

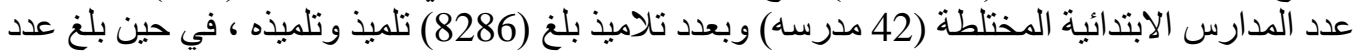

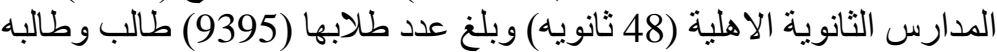

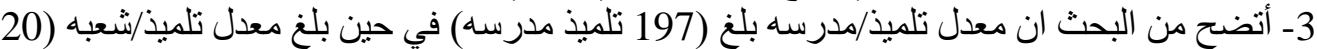

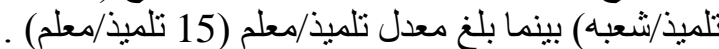

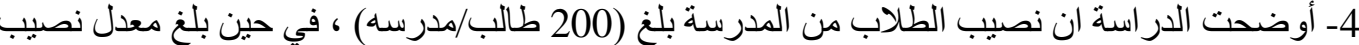

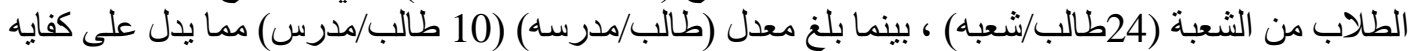

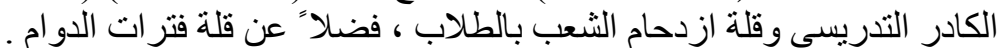




\section{المجلة الدولية اللهلوم الأنسانية والإمتاعية}

International Journal of Humanities and Social Sciences website:www.ijohss.com Email:editor@ijohss.com ISSN: 2415 - 4822

\section{العدد (14) أغطس 2020 \\ Volume (14) August 2020}

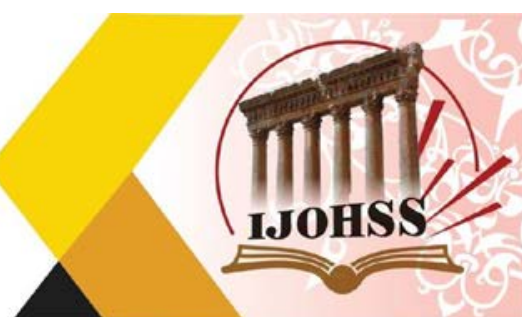

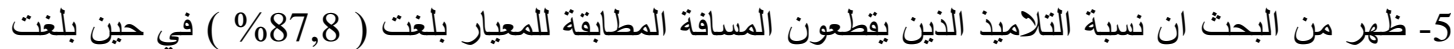

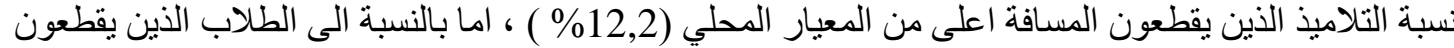
المسافة المطابقة للمعيار المحلي ( 45\% ) في حين بلغت نسبة الطلاب الذين بقطعون المسافة اعلى من المعيار (

6- بينت الدراسة ان درجة الرضا عن خدمات المؤسسات التعليمية الاهلية في مدينة الناصرية بلغ متوسطها

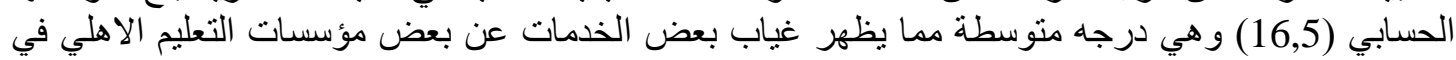

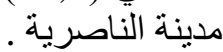

التوصيات

1- ضرورة التعاون بين التعليم الاهلي و التعليم الحكومي الرسمي من اجل ترصين العملية التربوية و التعليمية .

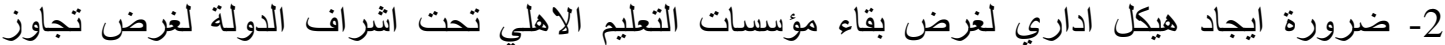

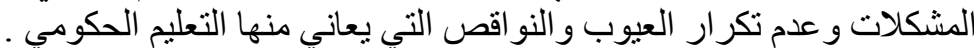

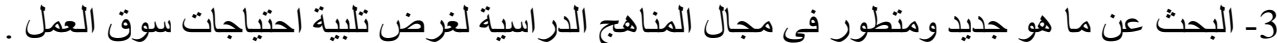

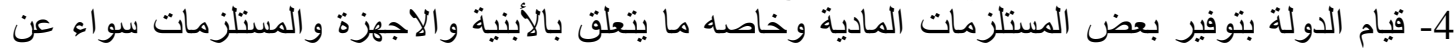
طريق السلف او تقديم القروض بوض بفوض الئد بسيطة .

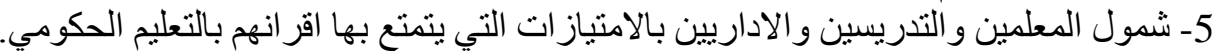

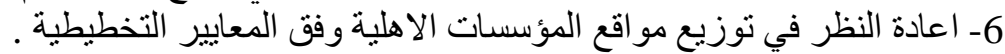

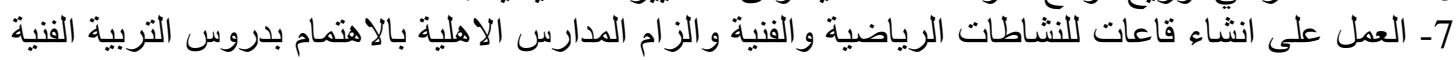

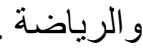
و اذ ما تحقق ذلك فأن التعليم الاهلي سوف يقوم بدوره الفاعل في نقل المجنمع العر اقي ليو اكب التطور و البناء .

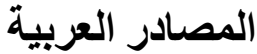

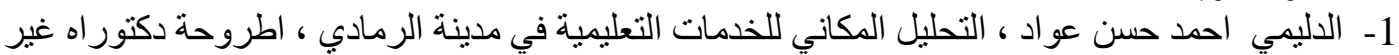

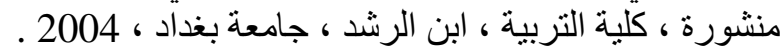

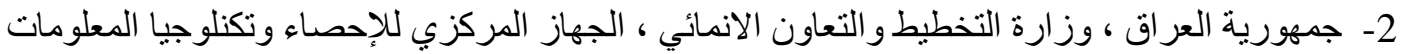

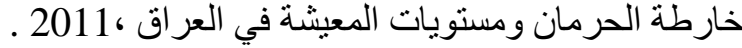

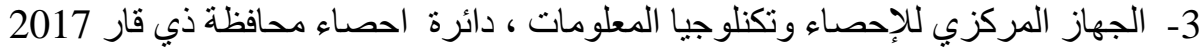

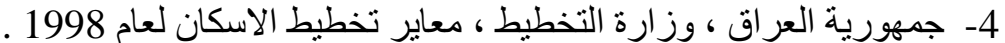
5- حسن حاتم حمودي ، تحليل واقع الخدمات التعليمية قضاء الكاظمية ، رسالة ماجستير غير منشورة ، كلية 6 الآداب ، جامعة بغداد 2006 ـ 2006 6- الزيادي حسين عليوي ناصر اقطاع التربية و التعليم ، در اسة مقدمه الى دائرة التتمية الإقليمية في محافظة ذي

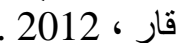

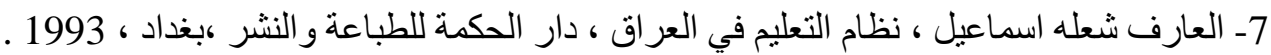

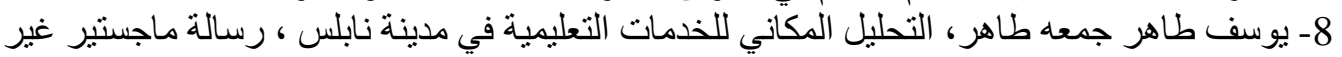

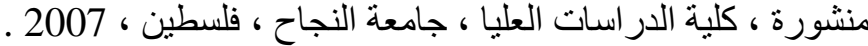

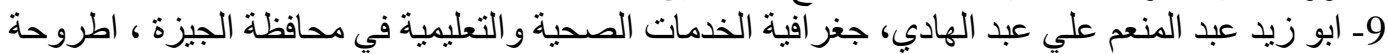

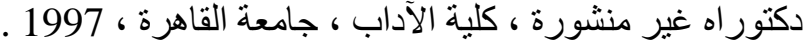
10 - وزارة التخطيط ، قسم الاسكان و المستوطنات السكنية ، هيئة التخطيط الاقليمية اسس ومعايير مباني

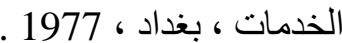




\section{References}

1- Al-Dulaimi, Ahmed Hassan Awad, spatial analysis of educational services in the city of Ramadi, unpublished doctoral dissertation, College of Education, Ibn AlRushd, University of Baghdad, 2004.

2- The Republic of Iraq, Ministry of Planning and Development Cooperation, Central Agency for Statistics and Information Technology Map of Deprivation and Living Standards in Iraq, 2011.

3- Central Agency for Statistics and Information Technology, Department of Statistics, Dhi Qar Governorate, 2017

4- Republic of Iraq, Ministry of Planning, Housing Planning Standards, 1998.

5- Hassan Hatem Hammoudi, Analysis of the Status of Educational Services, AlKadhimiya District, Unpublished Master Thesis, College of Arts, University of Baghdad 2006.

6- Al-Ziyadi Hussain Alaiwi Nasser, Education Sector, a study presented to the Regional Development Department in Dhi Qar Governorate, 2012.

7- Al-Aref Shoala Ismail, Education System in Iraq, Dar Al-Hekma for Printing and Publishing, Baghdad, 1993.

8- Youssef Taher Gomaa Taher, Spatial Analysis of Educational Services in Nablus, Unpublished Master Thesis, College of Graduate Studies, An-Najah University, Palestine, 2007.

9- Abu Zaid Abdel Moneim Ali Abdel Hady, Geography of Health and Education Services in Giza Governorate, Unpublished Doctoral dissertation, Faculty of Arts, Cairo University, 1997.

10 - Ministry of Planning, Department of Housing and Residential Settlements, Regional Planning Commission, Principles and Standards for Service Buildings, Baghdad, 1977.

11- A Stowing Thomas R.etal satisfaction with medical care (replication ) and theoretic reevaluation on .medical care march 1993.

12- C. Cobe, planning the hoctioh of school studies 10 , uNESCO, 1999 . 


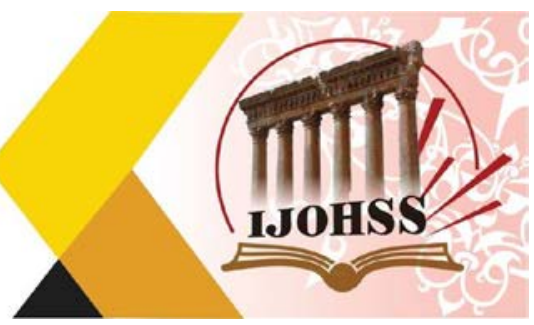

$$
\text { استمارة أستبانه }
$$

مديرية تربية محافظة ذي فار

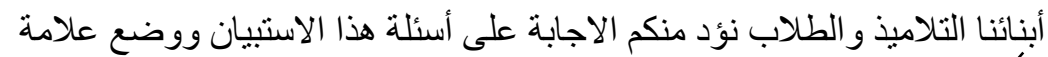

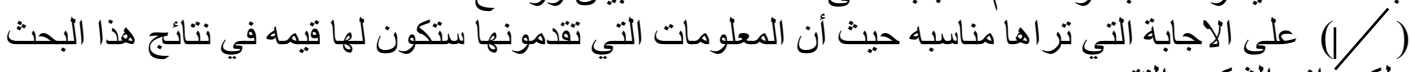

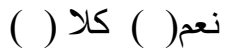

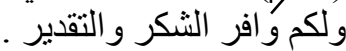

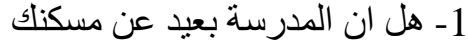

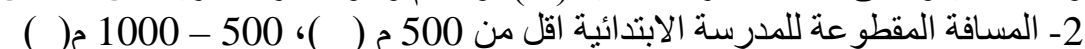

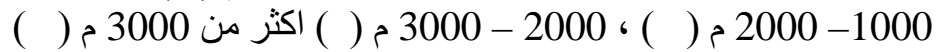

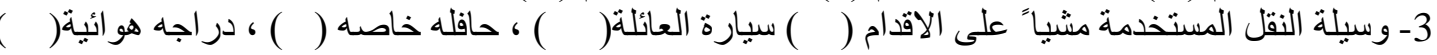

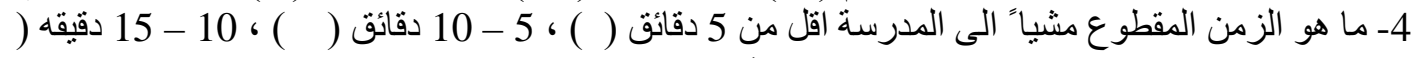

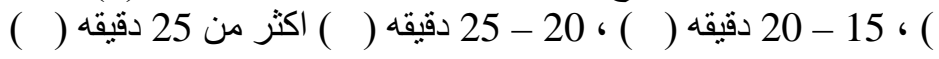
نعم( ) كما ( ) ( ) ( )

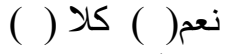

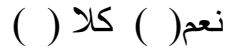

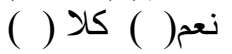
نعم( ) ( ) كلا ( ) ( ) ( ) ( ) ( )
نعم( ) ( ) كلا ( ) ( ) ( ) ( ) ( )

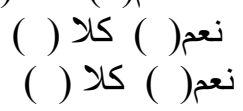
نعم( ) ( ) كلا ( ) ( ) ( ) ( ) ( )

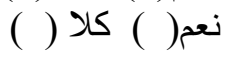

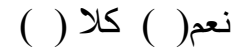

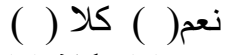
نعم( ) كلا ( ) ( ) ( ) ( )

درجة الرضا عن المؤسسة التعليمية الاهلية

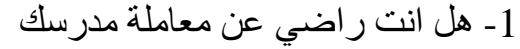
2- هل انت ر اضي عن عن فنرة دو امك في المدرسة

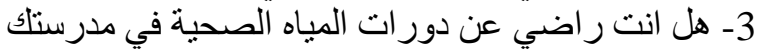

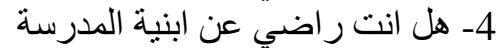

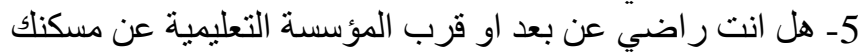

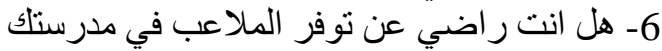

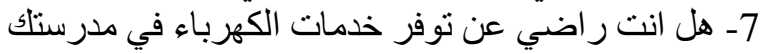

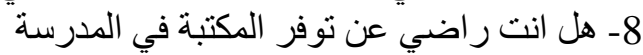

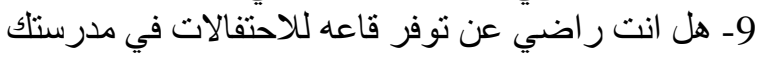

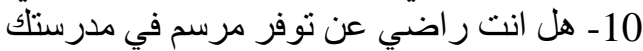
11- هل انت راضي عن نوفر اجهزة التبريد و التدفئة في مدرستك

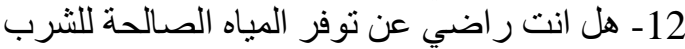
13- هل انت راضي عن نواضي توفر الرعاية الصحية في المدرسة 